\title{
Conformational Studies of Poly(9,9-dialkylfluorene)s in Solution Using NMR Spectroscopy and Density Functional Theory Calculations
}

\author{
Licínia L. G. Justino, ${ }^{*}, \dagger$, M. Luísa Ramos, ${ }^{\dagger, \S}$ Paulo E. Abreu, ${ }^{\dagger}$ Rui A. Carvalho, ${ }^{\dagger, \S}$ \\ Abilio J. F. N. Sobral, ${ }^{\dagger}$ Ullrich Scherf, ${ }^{\perp}$ and Hugh D. Burrows ${ }^{\dagger}$ \\ Departamento de Química, Faculdade de Ciências e Tecnologia, Universidade de Coimbra, \\ 3004-535 Coimbra, Portugal, Departamento de Bioquímica, Faculdade de Ciências e Tecnologia, Universidade \\ de Coimbra, 3001-401 Coimbra, Portugal, Centro de Neurociências e Biologia Celular, Departamento de \\ Zoologia, Faculdade de Ciências e Tecnologia, Universidade de Coimbra, 3004-517 Coimbra, Portugal, \\ Makromolekulare Chemie, Bergische Universität Wuppertal, D-42097 Wuppertal, Germany
}

Received: March 24, 2009; Revised Manuscript Received: June 29, 2009

\begin{abstract}
Relationships have been obtained between intermonomer torsional angle and NMR chemical shifts $\left({ }^{1} \mathrm{H}\right.$ and ${ }^{13} \mathrm{C}$ ) for isolated chains of two of the most important poly(9,9-dialkylfluorenes), poly[9,9-bis(2-ethylhexyl)fluorene-2,7-diyl] (PF2/6) and the copolymer poly(9,9-dioctylfluorene-co-[2,1,3]benzothiadiazole-4,7-diyl) (F8BT), using DFT calculations. The correlations provide a model for NMR spectral data interpretation and the basis for analysis of conformational changes in poly(9,9-dialkylfluorene-2,7-diyl)s. The correlations obtained for PF2/6 indicate that the ${ }^{13} \mathrm{C}$ chemical shifts of the aromatic carbons close to the intermonomer connection $(\mathrm{C} 1, \mathrm{C} 2$, and $\mathrm{C} 3)$ have minimum values at planar conformations $\left(0^{\circ}\right.$ and $\left.180^{\circ}\right)$ and maximum values at $90^{\circ}$ conformations. In contrast, the ${ }^{1} \mathrm{H}$ chemical shifts of the corresponding aromatic ortho protons $(\mathrm{Ha}$ and $\mathrm{Hb})$ are greatest for planar conformations, and the minimum values are seen for $90^{\circ}$ conformations. For the F8BT copolymer, similar relationships are observed for the ${ }^{1} \mathrm{H}(\mathrm{Ha}, \mathrm{Hb}$, and $\mathrm{Hc})$ aromatic shifts. Considering the aromatic carbons of F8BT, the behavior of $\mathrm{C} 2, \mathrm{C} 4, \mathrm{C} 5$, and $\mathrm{C} 6$ is similar to that found for the PF2/6 carbons. However, $\mathrm{C} 1$ and $\mathrm{C} 3$ of the fluorene moiety behave differently with varying torsion angle. These are in close proximity to the fluorene-benzothiadiazole linkage and are markedly affected by interactions with the thiadiazole unit such that $\delta_{\mathrm{C} 1}$ is a maximum for $180^{\circ}$ and a minimum for $0^{\circ}$, whereas $\delta_{\mathrm{C} 3}$ is a maximum for $0^{\circ}$ and minimum for $180^{\circ}$. We have studied the ${ }^{1} \mathrm{H}$ and ${ }^{13} \mathrm{C}$ spectra of the two polymers at temperatures between $-50{ }^{\circ} \mathrm{C}$ and $+65^{\circ} \mathrm{C}$. The observed changes to higher or lower frequency in the aromatic resonances were analyzed using these theoretical relationships. Fluorescence studies on PF2/6 in chloroform solution suggest there are no significant interchain interactions under these conditions. This is supported by variabletemperature NMR results. Polymer-solvent and polymer intramolecular interactions were found to be present and influence all of the alkylic and one of the aromatic ${ }^{1} \mathrm{H}$ resonances $(\mathrm{Hb})$. The detailed attribution of the ${ }^{1} \mathrm{H}$ and ${ }^{13} \mathrm{C}$ NMR spectra of the two polymers was made prior to the establishment of the relationships between torsion angle and NMR chemical shifts. This was carried out through DFT calculation of the ${ }^{1} \mathrm{H}$ and ${ }^{13} \mathrm{C}$ shielding constants of the monomers, coupled with distortionless enhancement by polarization transfer and heteronuclear correlation NMR spectra. Several DFT levels of calculation were tested for both optimization of structures and shielding constants calculation. The B3LYP/6-31G $(\mathrm{d}, \mathrm{p})$ method was found to perform well in both cases.
\end{abstract}

\section{Introduction}

Conjugated organic polymers have emerged as an important class of molecules for use as the active material in electronic and optoelectronic devices. Their particular physical and chemical characteristics, combining the electronic properties of semiconductors or metals with the low cost and the ease of processing of organic polymers, make them especially attractive in the development of new technologies. Currently, interest is being focused on the design of conjugated polymers with optimized properties for applications in areas such as light emitting diodes (LEDs), thin-film transistors, sensors, and

\footnotetext{
* Corresponding author. Phone: +351-239-854453. Fax: +351-239827703. E-mail: liciniaj@qui.uc.pt.

Departamento de Química, Universidade de Coimbra.

${ }^{\S}$ Centro de Neurociências e Biologia Celular, Universidade de Coimbra.

* Departamento de Bioquímica, Universidade de Coimbra.

${ }^{\perp}$ Bergische Universität Wuppertal.
}

photovoltaic cells. ${ }^{1,2}$ Conjugated polymers are also finding applications as artificial muscles, corrosion inhibitors, electronic textiles, in nerve cell communications, ${ }^{3}$ and, potentially, in data storage systems. ${ }^{4,5}$

Among these polymers, poly(9,9-dialkylfluorenes) (PFs) and related copolymers are particularly important because of their chemical and thermal stability, blue light emission, high photoluminescence (PL) quantum efficiency, and ease of property tuning by copolymerization. ${ }^{6-9}$ Alkyl chains can be introduced at the fluorene C-9 position, offering the possibility of controlling the polymer solubility, liquid crystallinity, chirality, and at the same time modulating interchain interactions in films. Although the rigid fluorene monomer units are not affected by the inclusion of the alkyl side chains, this may, however, influence intrachain conformation, particularly in nondilute solutions, and will also influence packing in films, where branched alkyl chains, such as in PF2/6, help limit 


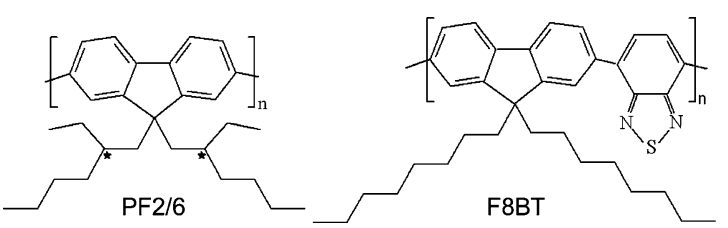

Figure 1. Chemical structures of PF2/6 and F8BT.
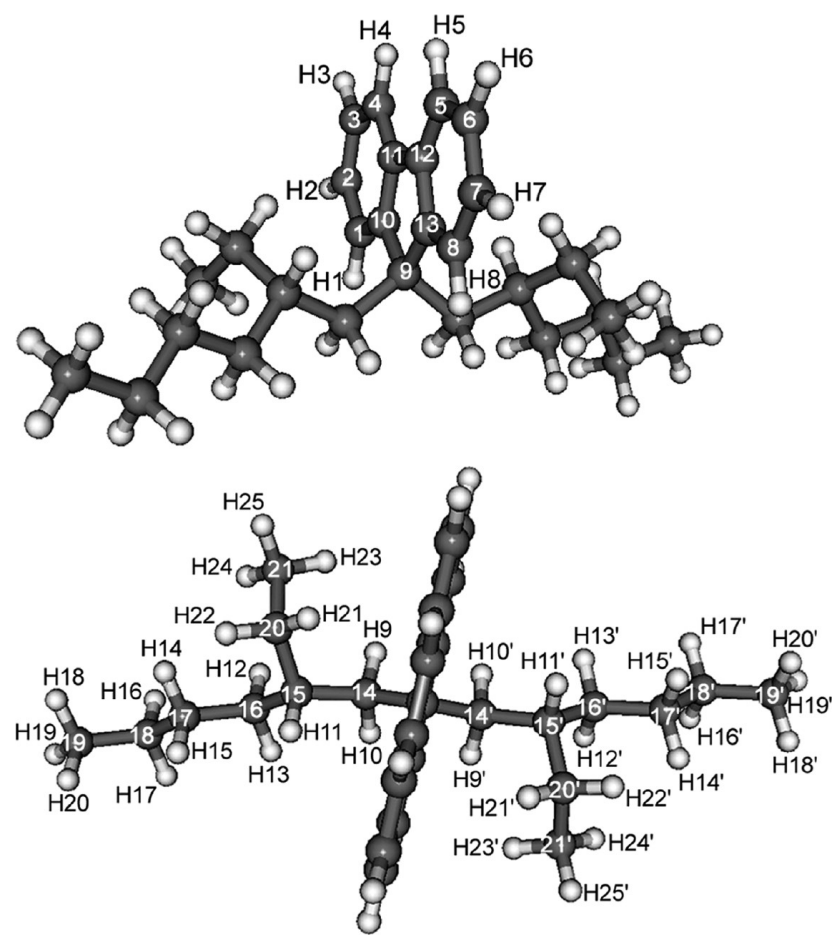

Figure 2. Structure of PF2/6 monomer (as $S, S$ or $R, R$ isomer) optimized at the B3LYP/6-31G(d,p) level.

interchain interactions. Thus, poly[9,9-bis(2-ethylhexyl)fluorene2,7-diyl] (PF2/6) and poly(9,9-dioctylfluorene-2,7-diyl) (PF8) are structural archetypal polyfluorenes (PFs), but despite their chemical resemblance, they present some striking distinctive features in solution and in films. In particular, PF2/6 generally adopts a wormlike chain conformation in dilute solution, ${ }^{10}$ whereas this leads to a helical structure in thin films. ${ }^{11,12}$ In contrast, the PF8 backbone conformation can vary from an almost planar structure, conventionally referred to as the $\beta$-phase $\left(C_{\beta}\right.$ isomer), with torsion angles from 160 to $165^{\circ}$, to less planar structures $\left(C_{\alpha}\right.$ and $C_{\gamma}$ isomer families), with torsion angles around $135^{\circ}$ and $150^{\circ} .{ }^{13}$ Further, in studies with poly $(9,9-$ dialkylfluorene)s with different side chains ${ }^{14,15}$ and random copolymers of PF2/6 and PF8, it has been shown that the side chain length and branching can have a dramatic effect on both solution structure and phase behavior. ${ }^{16}$ Moreover, solvent can have a dramatic influence on the structure and aggregation behavior of PFs. ${ }^{17}$

The study of the structural and electronic properties of polyfluorenes, both in solution and in solid state, is of key importance for the understanding of the properties of homologous polymer and oligomer systems, particularly in view of their applications in optoelectronic devices. Furthermore, the crystallinity and molecular packing of a polymer is related to a large extent to its backbone conformation. NMR has frequently been used in polymer chemistry to study structure, conformation, and defects, and its value in the particular case of PFs has been confirmed. ${ }^{18}$ In addition, it complements scattering techniques, such as small-angle X-ray and neutron scattering by reporting on a smaller distance scale. ${ }^{15}$ To obtain the maximum advantage of this powerful technique, detailed spectral assignment is a prerequisite. However, although partial assignment has been made of the NMR spectra of a number of polyfluorenes, ${ }^{18,19}$ full assignments are still lacking. For this, the combination of NMR spectroscopy with quantum mechanical calculations opens a wide scope of possibilities for obtaining further insight into the structure-properties relationships of these materials. The main objective of this study is to find relationships that allow the interpretation of the easily obtainable NMR chemical shifts of this class of polymer as a tool for conformational analysis. These studies will be carried out for PF2/6, taken as archetypal for PF homopolymers. Additionally, they will also be carried out for poly(9,9-dioctylfluorene-co-[2,1,3]benzothiadiazole-4,7diyl) (F8BT), an important copolymer of fluorene and the electron-deficient [2,1,3]benzothiadiazole (BT) comonomer, which emits in the green, and is valuable as a charge transport layer in devices. ${ }^{20}$ Theoretical methods that include electron correlation ( $a b$ initio and density functional theory, DFT) are known to describe the geometry of organic molecules as well as their energetics in a satisfactory manner. ${ }^{21}$ The value of DFT in simulations on poly(9,9-dialkylfluorene-2,7-diyl) polymers has recently been reported. ${ }^{22}$ This paper complements that work in a combined experimental and theoretical study coupling ${ }^{1} \mathrm{H}$ and ${ }^{13} \mathrm{C}$ NMR spectroscopy in dilute solution with DFT calculations for isolated molecules to address the questions referred to above.

\section{Experimental Section}

Computational Details. All the molecular optimizations were performed by DFT without symmetry constraints using the GAMESS $^{23}$ code. The calculations employed the B3LYP (Becke three-parameter Lee-Yang-Parr exchange correlation functional, which combines the hybrid exchange functional of Becke $^{24}$ with the correlation functional of Lee, Yang, and Parr $(\mathrm{LYP})^{25}$ ). In the optimization of the PF2/6 monomer, several different basis sets for the expansion of the Kohn-Sham orbitals were compared; in particular, the $3-21 \mathrm{G}(\mathrm{d}), 6-31 \mathrm{G}(\mathrm{d}, \mathrm{p})$, and $6-31+G(d)$ standard basis sets. For these structures, the nuclear shieldings were computed at the B3LYP/GIAO (gauge-including atomic orbital method) level using the $3-21 \mathrm{G}(\mathrm{d}), 6-31 \mathrm{G}(\mathrm{d}, \mathrm{p})$, and $6-31++\mathrm{G}(\mathrm{d}, \mathrm{p})$ basis sets. For the structure obtained using the $3-21 \mathrm{G}(\mathrm{d})$ basis sets, the shieldings were also computed at the HF/GIAO/3-21G(d) level. The ${ }^{1} \mathrm{H}$ and ${ }^{13} \mathrm{C}$ NMR chemical shifts were also calculated for the optimized geometry of the F8BT monomer. The structure was optimized at the B3LYP/ 6-31G(d,p) level, and the NMR chemical shifts were calculated at the B3LYP/GIAO/6-31G(d,p) level. The NMR calculations were carried out with the NWCHEM ${ }^{26}$ program employing a fine integration grid (FINE option). ${ }^{13} \mathrm{C}$ and ${ }^{1} \mathrm{H}$ relative chemical shifts $(\delta)$ are given with respect to the absolute shielding values $(\sigma)$ of tetramethylsilane (TMS) obtained at the same computational level $\left(\delta=\sigma_{\text {ref }}-\sigma\right)$.

The effect of the interunit torsion angle on ${ }^{1} \mathrm{H}$ and ${ }^{13} \mathrm{C}$ NMR chemical shifts was analyzed for the PF2/6 dimer and the F8BT monomer (the alkyl chains at the C-9 positions were replaced by methyl groups to reduce the computation time) starting from the structures optimized at the B3LYP/ $6-31 \mathrm{G}(\mathrm{d}, \mathrm{p})$ level and varying the torsion angle by $10^{\circ}$ steps. The structures were not relaxed at each torsion angle. For each structure, the nuclear shieldings were computed at the B3LYP/6-31G $(\mathrm{d}, \mathrm{p})$ level and converted into relative chemical shifts as indicated above. 
NMR and Fluorescence Methodology. PF2/6 and F8BT samples were prepared by dissolving a weighed amount of the polymer in chloroform- $d$ and were kept protected from light; all molar concentrations are given in terms of polymer repeat units. Chloroform is known to be a good solvent for polyfluorenes ${ }^{8}$ and is chosen to minimize the aggregation seen in aromatic solvents, such as toluene. ${ }^{15,17}$ The synthesis of PF2/6 has been described previously. ${ }^{27}$ F8BT was a gift from Professor J. Morgado, and its characteristics are reported elsewhere. ${ }^{28}$ Chloroform- $d\left(99.8\right.$ atom $\left.\%{ }^{2} \mathrm{H}\right)$ was purchased from Sigma-Aldrich, Inc., Germany. The ${ }^{1} \mathrm{H}$ and ${ }^{13} \mathrm{C}$ NMR spectra were recorded on a Varian UNITY-500 NMR spectrometer (at 499.824 and $125.692 \mathrm{MHz}$, respectively). The residual ${ }^{1} \mathrm{H}$ signal of $\mathrm{CDCl}_{3}(\delta=7.27 \mathrm{ppm})$ and the ${ }^{13} \mathrm{C}$ triplet centered at $\delta=77.23 \mathrm{ppm}$, relative to TMS, were used as internal references for ${ }^{1} \mathrm{H}$ and for ${ }^{13} \mathrm{C}$, respectively. The DEPT (distortionless enhancement by polarization transfer) and HETCOR (HETeronuclear CORrelation) spectra were recorded on the same spectrometer. For the variable temperature studies, the samples were allowed to attain thermal equilibrium before acquiring the spectra. Steady-state fluorescence spectra were obtained using a Horiba-Jobin-Ivon SPEX Fluorog 3-22 instrument. To minimize problems arising from inner filter effects and self-absorption, ${ }^{29}$ a frontface (FF) configuration was employed. All the fluorescence spectra were corrected for the wavelength response of the system.

\section{Results and Discussion}

Attribution of PF2/6 and F8BT ${ }^{13} \mathrm{C}$ and ${ }^{1} \mathrm{H}$ NMR Spectra. Before turning to the conformational study, we will start by carrying out a thorough attribution of the ${ }^{1} \mathrm{H}$ and ${ }^{13} \mathrm{C} \mathrm{NMR}$ spectra of PF2/6 and F8BT. The signals in these have not yet been assigned in detail, and the complete attribution is indispensable for establishing correlations between NMR chemical shifts and conformation and, hence, understanding the conformational behavior of PF derivatives. NMR parameters are extremely sensitive to the molecular orbital distribution and, consequently, to the structure and bonding of a molecule. This means that NMR spectroscopy can, in principle, be used to follow backbone conformational changes in PF derivatives under different solution or temperature conditions, provided that we have a model that correctly correlates the observed spectral changes with structure.

Figure 1 shows the chemical structures of PF2/6 and F8BT. The monomer of PF2/6 was optimized by DFT considering the isolated molecule at the B3LYP level using the 3-21G(d), 6-31G(d,p), and the $6-31+\mathrm{G}(\mathrm{d})$ basis sets. The optimization was followed by calculation of the NMR chemical shifts for the obtained structures. The theoretical calculation of the NMR chemical shifts will help clarify the attribution of the experimental NMR spectra. Additionally, the comparison between theoretical and experimental chemical shifts constitutes a valuable tool for evaluating the accuracy of the theoretical geometries calculated through this optimization. Following this, we have computed the NMR chemical shifts of the PF2/6 monomer at several DFT levels and also at the Hartree-Fock (HF) level. We have obtained the ${ }^{13} \mathrm{C}$ and ${ }^{1} \mathrm{H}$ NMR spectra of $\mathrm{PF} 2 / 6$ in $\mathrm{CDCl}_{3}$ solution, under conditions where we believe that we have isolated polymer chains. Figure 2 shows the equilibrium structure of the monomer at the B3LYP/6-31G(d,p) level, and in Tables 1 and 2, we compare the experimental PF2/6 ${ }^{13} \mathrm{C}$ and ${ }^{1} \mathrm{H}$ chemical shifts with the computed chemical shifts for the monomer at the different calculation levels.

The PF2/6 2-ethylhexyl side chains contain an asymmetric carbon (C15 and ${\mathrm{C} 15^{\prime}}^{\prime}$ in Figure 2). Consequently, there are three possible isomers: $R, R, S, S$, and the meso. Most experimental $\mathrm{PF} 2 / 6$ research, as in our case, uses racemic PF2/6, in which all three isomers are present in equal proportions. In our calculations, we have considered only the $S, S$ isomer (or the

TABLE 1: Comparison between ${ }^{13} \mathrm{C}$ NMR Experimental Chemical Shifts of PF2/6 and Calculated Values for PF2/6 Monomer

\begin{tabular}{|c|c|c|c|c|c|c|}
\hline Site & $\begin{array}{l}\text { B3/6-31+G(d)// } \\
\mathbf{B 3} / 6-31++G(d, p)^{a}\end{array}$ & $\begin{array}{l}\mathrm{B3} / 6-31 \mathrm{G}(\mathrm{d}, \mathrm{p}) / / \\
\mathrm{B3} / 6-31 \mathrm{G}(\mathrm{d}, \mathrm{p})\end{array}$ & $\begin{array}{l}\mathrm{B} 3 / 3-21 \mathrm{G}(\mathrm{d}) / / \\
\mathrm{B} 3 / 6-31 \mathrm{G}(\mathrm{d}, \mathrm{p})\end{array}$ & $\begin{array}{l}\text { B3/3-21G(d)// } \\
\text { B3/3-21G(d) }\end{array}$ & $\begin{array}{l}\text { B3/3-21G(d)// } \\
H F / 3-21 G(d)\end{array}$ & Expt. PF2/6 \\
\hline \multicolumn{7}{|l|}{$\begin{array}{l}\text { Aromatic } \\
\text { Region }\end{array}$} \\
\hline $\mathrm{C}(10) / \mathrm{C}(13)$ & $148.26 / 147.81$ & $149.34 / 149.48$ & $150.00 / 149.64$ & $134.79 / 134.77$ & $141.83 / 142.06$ & 151.45 \\
\hline $\mathrm{C}(11) / \mathrm{C}(12)$ & $139.72 / 137.19$ & $140.34 / 140.10$ & $140.21 / 140.10$ & $125.53 / 125.54$ & $131.64 / 131.51$ & 140.42 \\
\hline $\mathrm{C}(3) / \mathrm{C}(6)$ & $129.28 / 125.29$ & $123.04 / 123.04$ & $122.65 / 122.67$ & $110.48 / 110.54$ & $119.14 / 119.11$ & 126.37 \\
\hline$C(2) / C(7)^{b}$ & $131.97 / 120.69$ & $122.53 / 122.80$ & $122.21 / 122.49$ & $110.75 / 111.00$ & $120.46 / 120.29$ & $140.42^{\mathrm{c}}$ \\
\hline $\mathrm{C}(1) / \mathrm{C}(8)$ & $120.29 / 119.97$ & $118.77 / 118.21$ & $117.69 / 117.50$ & $107.46 / 107.03$ & $116.02 / 116.44$ & 123.21 \\
\hline $\mathrm{C}(4) / \mathrm{C}(5)$ & $119.42 / 122.25$ & $115.44 / 115.50$ & $115.28 / 115.27$ & $105.08 / 104.85$ & $114.39 / 114.68$ & 120.03 \\
\hline \multicolumn{7}{|l|}{$\begin{array}{l}\text { Alkylic } \\
\text { Region }\end{array}$} \\
\hline $\mathrm{C}(9)$ & 68.77 & 58.60 & 59.73 & 54.26 & 48.02 & 55.30 \\
\hline $\mathrm{C}(14) / \mathrm{C}\left(14^{\prime}\right)$ & $46.73 / 45.74$ & $47.09 / 47.30$ & $46.53 / 46.42$ & $40.54 / 40.40$ & $36.89 / 36.73$ & 44.72 \\
\hline $\mathrm{C}(15) / \mathrm{C}\left(15^{\prime}\right)$ & $37.94 / 35.89$ & $36.31 / 35.48$ & $37.04 / 37.49$ & $31.99 / 32.34$ & $28.38 / 28.37$ & 34.97 \\
\hline $\mathrm{C}(16) / \mathrm{C}\left(16^{\prime}\right)$ & $33.56 / 34.83$ & $37.10 / 37.79$ & $37.38 / 37.23$ & $31.73 / 31.59$ & $26.23 / 26.60$ & 34.39 \\
\hline $\mathrm{C}(17) / \mathrm{C}\left(17^{\prime}\right)$ & $29.40 / 33.63$ & $31.44 / 30.95$ & $32.34 / 32.71$ & $27.16 / 27.53$ & $24.25 / 24.51$ & 28.56 \\
\hline $\mathrm{C}(18) / \mathrm{C}\left(18^{\prime}\right)$ & $33.47 / 31.36$ & $26.24 / 26.76$ & $27.01 / 27.00$ & $22.15 / 22.07$ & $19.50 / 19.52$ & 27.35 \\
\hline $\mathrm{C}(20) / \mathrm{C}\left(20^{\prime}\right)$ & $22.54 / 21.52$ & $22.09 / 22.76$ & $22.61 / 23.10$ & $18.41 / 18.86$ & $15.27 / 15.65$ & 23.01 \\
\hline $\mathrm{C}(19) / \mathrm{C}\left(19^{\prime}\right)$ & $18.42 / 18.60$ & $15.76 / 15.75$ & $16.38 / 16.54$ & $13.56 / 13.67$ & $14.05 / 14.08$ & 14.27 \\
\hline $\mathrm{C}(21) / \mathrm{C}\left(21^{\prime}\right)$ & $10.69 / 7.60$ & $6.78 / 6.79$ & $7.07 / 7.08$ & $5.57 / 5.61$ & $6.42 / 6.47$ & 10.59 \\
\hline
\end{tabular}

${ }^{a}$ B3 stands for B3LYP; the notation indicates "level of geometry calculation//level of NMR chemical shifts calculation". ${ }^{b}$ In the polymer, the hydrogen atoms at the 2 and 7 positions of the monomer are substituted with the carbon atoms of a new monomer. ${ }^{c}$ Attribution based on integration of experimental ${ }^{13} \mathrm{C}$ aromatic signals. 
TABLE 2: Comparison between ${ }^{1} \mathrm{H}$ NMR Experimental Chemical Shifts of PF2/6 and Calculated Values for the PF2/6 Monomer

\begin{tabular}{|c|c|c|c|c|c|c|}
\hline Site & $\begin{array}{l}\mathbf{B} 3 / 6-31+G(d) / / \\
\mathbf{B} 3 / 6-31++G(d, p)^{\mathrm{a}}\end{array}$ & $\begin{array}{l}\mathrm{B3} / 6-31 \mathrm{G}(\mathrm{d}, \mathbf{p}) / / \\
\mathrm{B3} / 6-31 \mathrm{G}(\mathrm{d}, \mathrm{p})\end{array}$ & $\begin{array}{l}\text { B3/3-21G(d)// } \\
\text { B3/6-31G(d,p) }\end{array}$ & $\begin{array}{l}\text { B3/3-21G(d)// } \\
\text { B3/3-21G(d) }\end{array}$ & $\begin{array}{l}\text { B3/3-21G(d)// } \\
\text { HF/3-21G(d) }\end{array}$ & Expt. PF2/6 \\
\hline \multicolumn{7}{|l|}{ Aromatic } \\
\hline \multicolumn{7}{|l|}{ Region } \\
\hline $\mathrm{H} 4 / \mathrm{H} 5$ & $7.93 / 8.58$ & $7.98 / 7.87$ & $7.84 / 7.76$ & $7.37 / 7.34$ & $7.81 / 7.78$ & $7.82-7.83(\mathrm{~d})^{\mathrm{b}}$ \\
\hline H1/H8 & $6.93 / 7.47$ & $8.06 / 8.01$ & $7.85 / 7.83$ & $7.54 / 7.54$ & $7.46 / 7.45$ & 7.67 \\
\hline $\mathrm{H} 2 / \mathrm{H} 7$ & $6.89 / 7.69$ & $7.33 / 7.37$ & $7.21 / 7.25$ & $7.07 / 7.03$ & $7.34 / 7.35$ & $\mathrm{c}$ \\
\hline H3/H6 & $6.81 / 6.91$ & $7.31 / 7.34$ & $7.19 / 7.21$ & $6.90 / 6.85$ & $7.36 / 7.35$ & $7.64-7.67(d)$ \\
\hline \multicolumn{7}{|l|}{ Alkylic } \\
\hline \multicolumn{7}{|l|}{ Region } \\
\hline H9/H9' & $1.48 / 1.76$ & $3.02 / 2.97$ & $2.86 / 2.90$ & $2.91 / 2.94$ & $1.93 / 1.97$ & \multirow{2}{*}{ 2.14(b) } \\
\hline $\mathrm{H} 10 / \mathrm{H} 10$ & $1.37 / 1.40$ & $2.30 / 2.32$ & $2.11 / 2.23$ & $2.15 / 2.28$ & $1.28 / 1.42$ & \\
\hline H12/H12' & $1.13 / 0.57$ & $1.67 / 1.61$ & $1.56 / 1.59$ & $1.56 / 1.58$ & $0.86 / 0.91$ & \multirow{9}{*}{$\begin{array}{l}0.90-0.95(b) \\
0.70\end{array}$} \\
\hline H11/H11' & $0.59 / 0.90$ & $1.66 / 1.57$ & $1.44 / 1.49$ & $1.41 / 1.47$ & $0.20 / 0.29$ & \\
\hline H17/H17' & $1.34 / 1.07$ & $1.34 / 1.28$ & $1.24 / 1.22$ & $1.21 / 1.17$ & $0.81 / 0.84$ & \\
\hline H13/H13' & $1.03 / 0.58$ & $1.30 / 1.27$ & $1.15 / 1.12$ & $1.18 / 1.15$ & $0.43 / 0.45$ & \\
\hline H14/H14' & $0.97 / 0.90$ & $1.25 / 1.20$ & $1.21 / 1.29$ & $1.18 / 1.26$ & $0.72 / 0.79$ & \\
\hline H16/H16' & $1.21 / 1.15$ & $1.13 / 1.17$ & $1.05 / 1.03$ & $0.95 / 0.92$ & $0.75 / 0.76$ & \\
\hline $\mathrm{H} 15 / \mathrm{H} 15$ & $0.71 / 0.07$ & $0.97 / 0.96$ & $0.87 / 0.91$ & $0.93 / 0.98$ & $0.25 / 0.28$ & \\
\hline $\mathrm{H} 22 / \mathrm{H} 22^{\prime}$ & $1.38 / 0.84$ & $0.88 / 0.91$ & $0.80 / 0.84$ & $0.63 / 0.69$ & $0.10 / 0.16$ & \\
\hline $\mathrm{H} 21 / \mathrm{H} 21{ }^{\prime}$ & $0.09 / 0.17$ & $0.59 / 0.69$ & $0.43 / 0.62$ & $0.51 / 0.69$ & $-0.56 /-0.43$ & \\
\hline $\mathrm{H} 18,19,20 /$ & $0.81 / 0.79$ & $0.57 / 0.58$ & $0.61 / 0.57$ & $0.60 / 0.59$ & $0.70 / 0.71$ & 0.69 \\
\hline \multicolumn{7}{|l|}{$\mathrm{H} 18^{\prime}, 19^{\prime}, 20^{\prime}$} \\
\hline $\mathrm{H} 23,24,25 /$ & $0.42 / 0.34$ & $0.57 / 0.65$ & $0.53 / 0.56$ & $0.58 / 0.63$ & $0.19 / 0.26$ & 0.61 \\
\hline $\mathrm{H} 23^{\prime}, 24^{\prime}, 25^{\prime}$ & & & & & & \\
\hline
\end{tabular}

${ }^{a}$ B3 stands for B3LYP; the notation indicates "level of geometry calculation//level of NMR chemical shifts calculation". ${ }^{b}$ "d" stands for doublet, and "b" stands for broad. ${ }^{c}$ In PF2/6, the hydrogen atoms at the 2 and 7 positions of the monomer are substituted with carbon atoms of a new monomer.
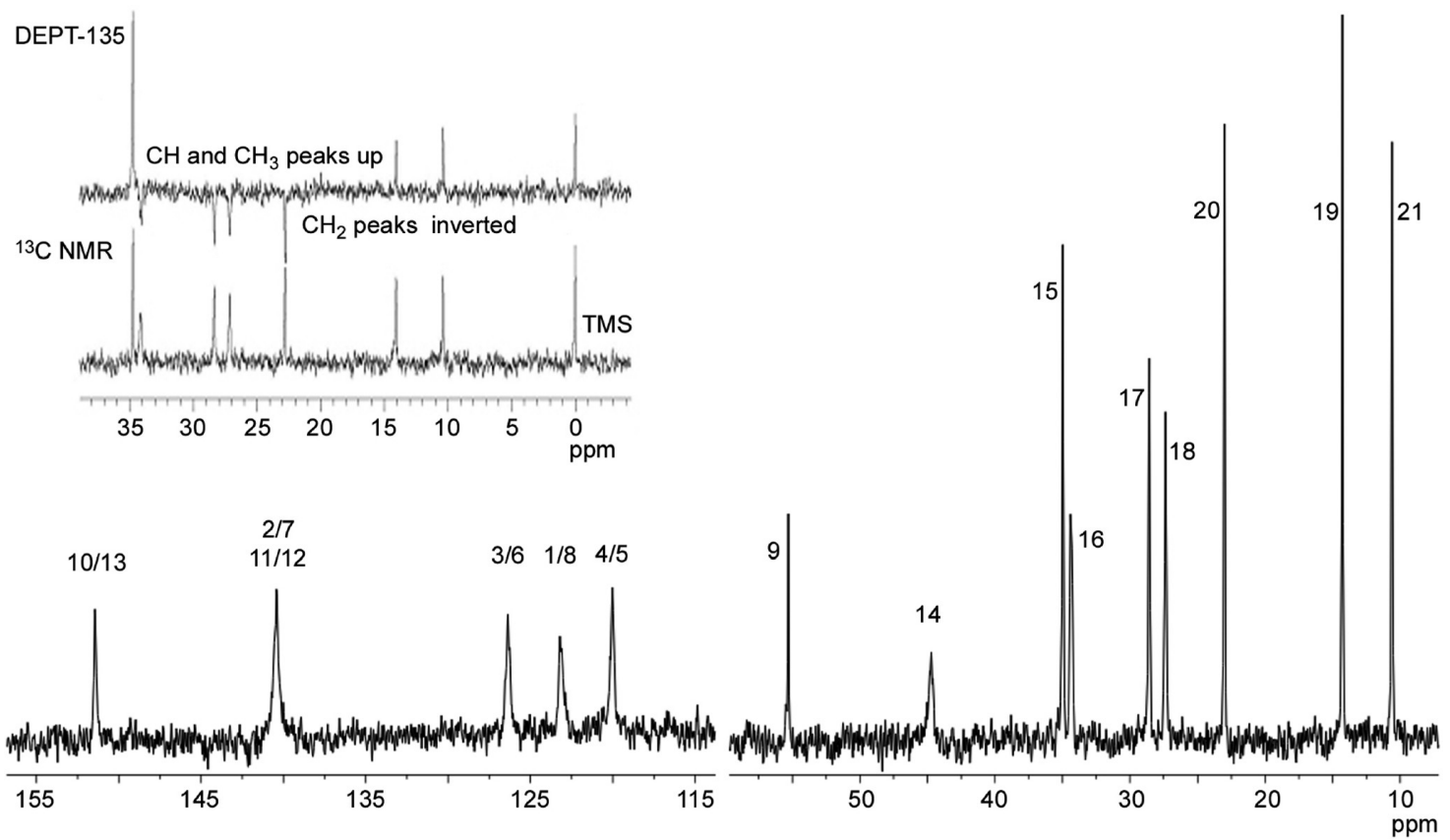

Figure 3. ${ }^{13} \mathrm{C}$ NMR spectrum of a PF2/6 $0.01 \mathrm{M}$ solution (in terms of repeat units) in $\mathrm{CDCl}_{3}$ at $298.15 \mathrm{~K}$ (numbering is as defined in Figure 2). Inset: DEPT spectrum of the same solution (only the section $0-35.5 \mathrm{ppm}$ of the alkylic region was detected due to the low concentration of the solution).

equivalent $R, R$ one). In terms of chemical shifts, these are identical, since NMR cannot distinguish between optical isomers. The meso isomer will have slightly different chemical shifts, but we do not expect these differences to be significant and will ignore them for the purpose of NMR chemical shift predictions. Any major differences would be likely to come from 


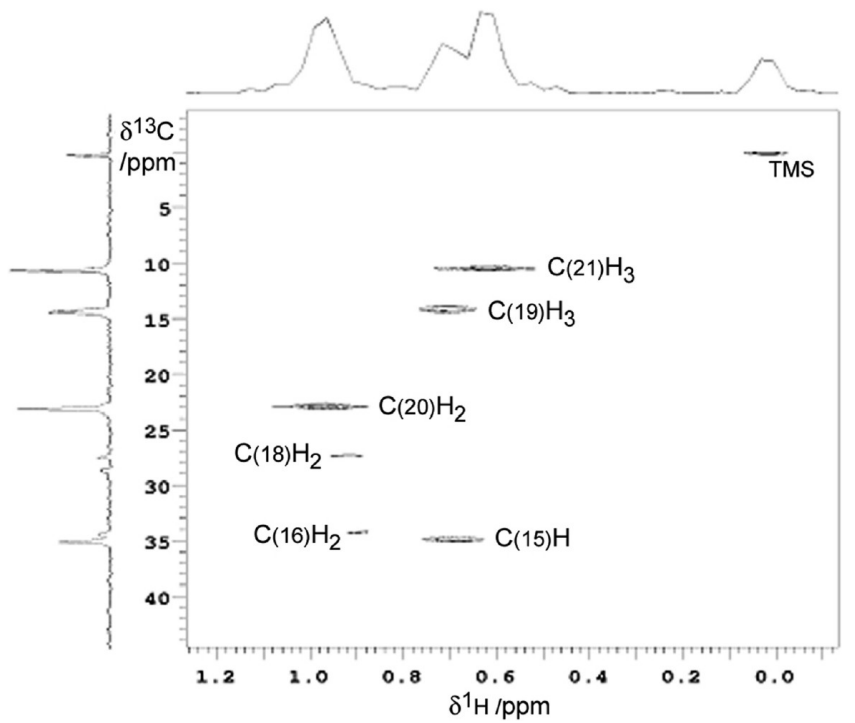

Figure 4. HETCOR spectrum of a PF2/6 $0.01 \mathrm{M}$ solution (in terms of repeat units) in $\mathrm{CDCl}_{3}$ at $298.15 \mathrm{~K}$ (only the section $\delta^{13} \mathrm{C}=0-35.5$ $\mathrm{ppm}$ of the alkylic region was detected due to the low concentration of the solution).

different intrachain or interchain interactions with the meso isomer, but these are not expected to be important under our experimental conditions.

We have calculated the ${ }^{13} \mathrm{C}$ and ${ }^{1} \mathrm{H}$ chemical shifts of the PF2/6 monomer at the HF/3-21G(d), B3LYP/3-21G(d), B3LYP/ 6-31G(d,p), and B3LYP/6-31++G(d,p) levels. In Table 1 we have compiled the ${ }^{13} \mathrm{C}$ results and can see that the B3LYP/3$21 \mathrm{G}(\mathrm{d}) / / \mathrm{HF} / 3-21 \mathrm{G}(\mathrm{d}){ }^{13} \mathrm{C}$ chemical shifts are systematically underestimated (the notation indicates [geometry optimization// NMR calculation] levels). A similar result is obtained for the B3LYP/3-21G(d)//B3LYP/3-21G(d) level of calculation. Here, the differences between predicted and experimental shifts are larger for the aromatic carbons and smaller for the alkylic carbons. Overall, the best results are obtained for the B3LYP/ 6-31G(d,p)//B3LYP/6-31G(d,p) and B3LYP/3-21G(d)//B3LYP/ 6-31G(d,p) levels, the two levels giving almost identical results with absolute differences between calculated and experimental shifts ranging from 0.08 to $5.52 \mathrm{ppm}$. Curiously, the use of diffuse basis functions in the optimization leads to a rather asymmetrical structure, as can be seen from the predicted chemical shifts. The quality of the results at this level is similar to that of the 6-31G(d,p)//6-31G(d,p) and 3-21G(d)//6-31G(d,p) levels. The attribution of the ${ }^{13} \mathrm{C}$ NMR spectrum of $\mathrm{PF} 2 / 6$ is relatively simple on the basis of the chemical shift predictions. Despite some small differences between the computed and the experimental shifts at the $6-31 \mathrm{G}(\mathrm{d}, \mathrm{p}) / / 6-31 \mathrm{G}(\mathrm{d}, \mathrm{p})$ and $3-21 \mathrm{G}(\mathrm{d}) / /$ $6-31 G(d, p)$ levels, there is a clear correspondence between the calculated and the experimental chemical shifts, which is the same whatever the calculation level (except for the results at the $6-31+\mathrm{G}(\mathrm{d}) / / 6-31++\mathrm{G}(\mathrm{d}, \mathrm{p})$ level, where the asymmetry of the structure makes it difficult to establish a relationship). The correspondence between experimental and computed shifts is presented in Table 1. The calculations systematically predict larger chemical shifts for the quaternary aromatic carbons $\mathrm{C10}$ / $\mathrm{C} 13$ and $\mathrm{C} 11 / \mathrm{C} 12$, and we therefore attribute the two signals at higher frequency to these two carbons. $\mathrm{C} 2 / \mathrm{C} 7$ in the monomer are $\mathrm{CH}$ carbons and, thus, have a ${ }^{13} \mathrm{C}$ shift around $122 \mathrm{ppm}$ at the 6-31G(d,p)//6-31G(d,p) level. However, in the polymer, they become quaternary carbons because the $\mathrm{H}$ atoms at these positions are replaced by the carbons of new monomer units. Since these carbons become quaternary, we expect their chemical shifts to be at higher frequency; integration of the aromatic signals in the ${ }^{13} \mathrm{C}$ spectrum suggests that they are at 140.42 ppm.

When analyzing the differences between the calculated and the experimental chemical shifts, we should take into account that we are comparing theoretical chemical shifts obtained for the static equilibrium geometry of the monomer in the gas phase (i.e., as an isolated molecule) with the experimental shifts obtained for the polymer in solution at room temperature. There are, therefore, numerous factors that are not included in our calculations, such as temperature (rovibrational) effects, zeropoint energy effects, intra- and intermolecular (including solvent) interactions, and most importantly, we are just considering one small repeat unit of the polymer and not the large macromolecules with several hundreds repeat units that exist in solution. In addition, it is important experimentally that the polymers are present as isolated chains and do not aggregate in solution. This will be discussed in detail later in the paper.

The theoretical predictions agree perfectly with the experimental DEPT spectrum of PF2/6 (inset of Figure 3). The DEPT spectrum shows that the signals at 10.59 and 14.27 belong to the terminal alkyl $\mathrm{CH}_{3}$ carbons; the signals at 23.01, 27.35, 28.56, and 34.39 belong to the alkyl $\mathrm{CH}_{2}$ carbons; and the signal at 34.97 belongs to the alkyl $\mathrm{CH}$ carbons, exactly as the calculations indicate. The complete attribution of the ${ }^{13} \mathrm{C} N M R$ spectrum of PF2/6 is shown in Figure 3.

Table 2 contains the theoretical ${ }^{1} \mathrm{H}$ chemical shifts obtained at the same levels used to calculate the ${ }^{13} \mathrm{C}$ shifts. ${ }^{1} \mathrm{H}$ shifts are especially sensitive to small electronic density variations, such as those caused by intermolecular interactions and, thus, are more difficult to calculate accurately for macromolecules in solution. The B3LYP/3-21G(d)//HF/3-21G(d) method performs reasonably well for the aromatic protons, but it strongly underestimates some of the alkylic protons. This is mostly due to the neglect of correlation effects in the calculation of the shifts at the HF level. In addition, the results at the $6-31+\mathrm{G}(\mathrm{d}) / /$ $6-31++G(d, p)$ level are very irregular due to the asymmetry of the geometry at this level. The best results are obtained using the 6-31G(d,p)//6-31G(d,p) and 3-21G(d)//6-31G(d,p) basis. The $\mathrm{CH}_{3}$ chemical shifts are well-predicted at both of these levels, with differences between calculated and experimental shifts ranging from 0.04 to $0.12 \mathrm{ppm}$. The $\mathrm{CH}$ alkylic proton and most of the $\mathrm{CH}_{2}$ protons (except $\mathrm{H} 15, \mathrm{H} 16, \mathrm{H} 21$, and $\mathrm{H} 22$ ), however, are slightly overestimated. For the $\mathrm{CH}_{2}$ and $\mathrm{CH}$ alkylic protons, the differences at these two calculation levels vary from 0.00 to $0.88 \mathrm{ppm}$. The calculations predict a distinctly larger chemical shift for the $\mathrm{CH}_{2}$ protons attached to $\mathrm{C} 14$, and consequently, we attribute the experimental shift at $2.14 \mathrm{ppm}$ to these protons. The aromatic $\mathrm{H} 1 / \mathrm{H} 8$ and $\mathrm{H} 4 / \mathrm{H} 5 \mathrm{CH}$ protons are wellreproduced, but the $\mathrm{H} 3 / \mathrm{H} 6$ values are slightly underestimated. We can analyze these results in conjunction with the HETCOR spectrum of PF2/6 (Figure 4) and the ${ }^{13} \mathrm{C}$ theoretical attribution established in Table 1 and Figure 3.

From the HETCOR results, we know that the methylinic $\mathrm{H}$ atoms attached to $\mathrm{C} 21(\mathrm{H} 23-\mathrm{H} 25)$ have a $\delta^{1} \mathrm{H}$ of $0.61 \mathrm{ppm}$. Similarly, we know that the methylinic H18-H20 (attached to $\mathrm{C} 19)$ have a $\delta^{1} \mathrm{H}$ of $0.69 \mathrm{ppm}$. In the methylene and $\mathrm{CH}$ region, the $\mathrm{H}$ atoms attached to $\mathrm{C} 16$ (H12, H13), C18 (H16, H17), and $\mathrm{C} 20$ (H21, H22) lead to the broad signal from 0.90 to $0.95 \mathrm{ppm}$, and the $\mathrm{H}$ atom attached to $\mathrm{C} 15$ has $\delta^{1} \mathrm{H} \sim 0.70 \mathrm{ppm}$. Figure 5 shows the ${ }^{1} \mathrm{H}$ NMR spectrum of a $\mathrm{PF} 2 / 6$ solution in $\mathrm{CDCl}_{3}$. The signal at $1.55 \mathrm{ppm}$ is due to the residual $\mathrm{H}_{2} \mathrm{O}$ present in the solvent. The calculations indicate that in the monomer, H1/ $\mathrm{H} 8$ and $\mathrm{H} 4 / \mathrm{H} 5$ will be more deshielded than $\mathrm{H} 2 / \mathrm{H} 7$ and $\mathrm{H} 3$ / 


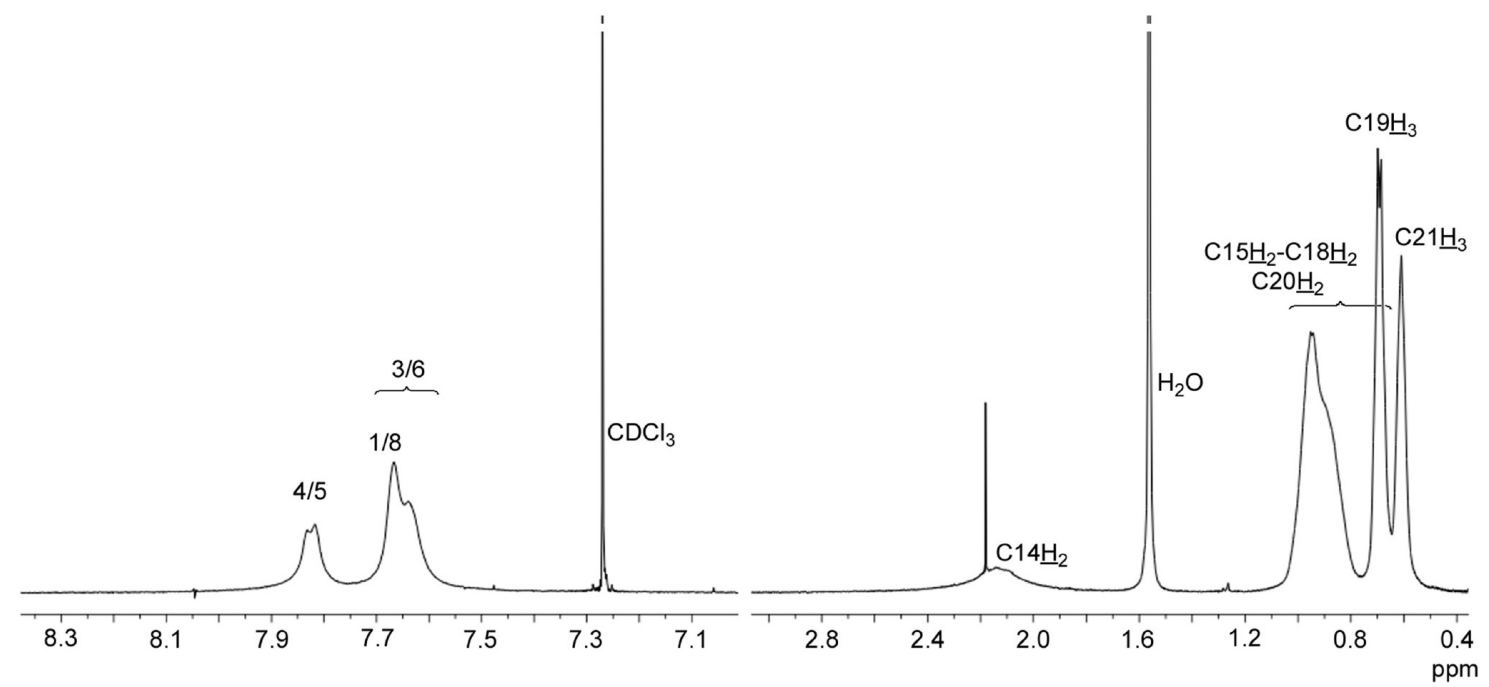

Figure 5. ${ }^{1} \mathrm{H}$ NMR spectrum of a PF2/6 0.01 M solution (in terms of repeat units) in $\mathrm{CDCl}_{3}$ at $298.15 \mathrm{~K}$ (numbering is as defined in Figure 2).
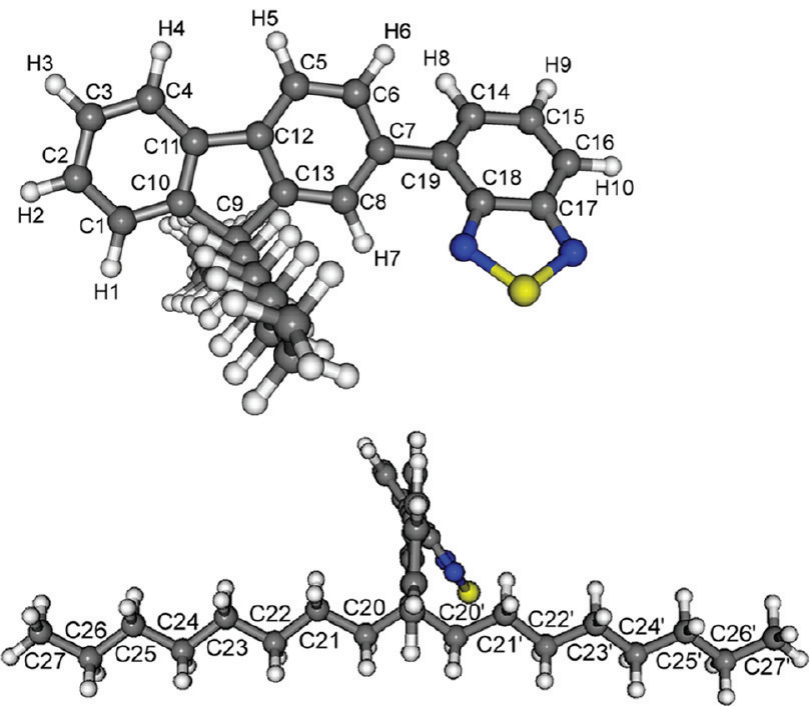

Figure 6. Structure of the F8BT monomer optimized at the B3LYP/ $6-31 G(d, p)$ level. Note that the numbering of the individual atoms in this structure does not correspond to that in the IUPAC name for the compound.

H6. In the polymer, the $\mathrm{H} 2 / \mathrm{H} 7$ protons will be missing, since these will be substituted by the carbon atoms of adjacent new monomeric units. Consequently, the H1/H8 signal will turn into a singlet, and the $\mathrm{H} 4 / \mathrm{H} 5$ and $\mathrm{H} 3 / \mathrm{H} 6$ signals will each turn into a doublet. We also expect the aromatic shifts to be slightly deshielded in the polymer relative to the monomer because of the inclusion of carbon atoms at the 2 and 7 positions. On the basis of the theoretical shifts and integration of the aromatic signals, we attribute the aromatic protons as depicted in Figure 5.

For the attribution of the ${ }^{1} \mathrm{H}$ and ${ }^{13} \mathrm{C}$ NMR signals of F8BT, we have used the same procedure. Figure 6 shows the DFT optimized structure of the monomer, and Table 3 compares the experimental chemical shifts obtained for the polymer in solution with the theoretical shifts calculated for the monomer. The attributions of the ${ }^{1} \mathrm{H}$ and ${ }^{13} \mathrm{C}$ spectra are presented in Table 3 . On the basis of the performance of the different methods tested for PF2/6, we have chosen the B3LYP/6-31G(d,p) levels for both structure optimization and NMR shielding calculations.

The pairs of atoms indicated in the "site" column of Table 3 are nonequivalent in the monomer (and the calculations reflect this); however, in the polymer, they will be equivalent due to symmetry. The chemical shifts of the carbon atoms C1, C3, $\mathrm{C} 4$, and $\mathrm{C} 15$ and of the hydrogen atoms H1, H3, H4, and H9 will be strongly affected when going from the monomer to the polymer due to substitution of the $\mathrm{H} 2$ and $\mathrm{H} 10$ by the benzothiadiazole and fluorene units, respectively. Thus, we have not considered their calculated chemical shifts (in brackets in Table 3) for the purpose of establishing the attribution. Instead, their chemical shifts in the polymer will be much closer to the value of the corresponding equivalent atom. Similarly, C2 and C16 chemical shifts were not considered, since their chemical environment in the monomer does not reflect their chemical environment in the polymer. Figure $7 \mathrm{a}$ and $\mathrm{b}$ shows, respectively, the ${ }^{1} \mathrm{H}$ and ${ }^{13} \mathrm{C}$ NMR spectra of F8BT with the attribution of signals.

Despite eventual structural and electronic differences between pure fluorene and the fluorene-2,7-diyl moieties incorporated in the PF2/6 and F8BT polymers, the ${ }^{13} \mathrm{C}$ shifts of the aromatic carbons of the polymers (Figures 3 and $7 \mathrm{~b}$ ) follow the same sequence of shifts as the aromatic carbons in fluorene (fluorene ${ }^{13} \mathrm{C}$ attribution was obtained from the Internet NMR spectral database operated by the National Institute of Materials and Chemical Research of $\operatorname{Japan}^{30}$ ).

Fluorescence Studies on Aggregation Behavior of PF2/6 in Chloroform. At the concentrations used in these NMR experiments, PF2/6 is known to aggregate in aromatic solvents, such as toluene. ${ }^{17}$ Since it is difficult solely from NMR spectroscopy to rule out interchain aggregations with polyfluorenes, ${ }^{15}$ we have studied the behavior of PF2/6 in chloroform solution using fluorescence spectroscopy, which gives direct information on any perturbations to the aromatic backbone arising from $\pi$-stacking or other effects. These experiments are not easy to perform in the same concentration range used in the NMR study due to inner filter and reabsorption effects. ${ }^{29}$ Fluorescence spectra have been measured for concentrated and dilute solutions of PF2/6 in chloroform, with excitation at the long wavelength edge of the absorption (390 nm). Typical normalized spectra are shown in Figure 8. The main difference from the concentrated solution is a loss of the first vibrational component around $414 \mathrm{~nm}$ and a slight apparent red shift in the second component in the $445-450 \mathrm{~nm}$ region. Although the slight shift in this band with the concentrated solution may suggest some kind of aggregation, the dominant effect is clearly 
TABLE 3: Comparison between NMR Experimental Chemical Shifts of F8BT and Calculated Chemical Shifts for the F8BT Monomer (B3LYP/6-31G(d,p)//B3LYP/6-31G(d,p)

\begin{tabular}{|c|c|c|c|c|}
\hline Site & $\delta^{13} \mathrm{C}_{\text {calc. }}$ & $\delta^{13} \mathrm{C}_{\text {expt. }}$ & $\delta^{1} \mathrm{H}_{\text {calc. }}$ & $\delta^{1} \mathrm{H}_{\text {expt. }}$ \\
\hline \multicolumn{5}{|l|}{ Quaternary C } \\
\hline $\mathrm{C} 18 / \mathrm{C} 17$ & $151.92 / 152.82$ & 154.58 & & \\
\hline $\mathrm{C} 13 / \mathrm{C} 10$ & $149.58 / 149.30$ & 152.01 & & \\
\hline $\mathrm{C} 12 / \mathrm{C} 11$ & $141.71 / 139.51$ & 141.09 & & \\
\hline $\mathrm{C} 7 / \mathrm{C} 2$ & $136.65^{\mathrm{a}}$ & 136.70 & & \\
\hline $\mathrm{C} 19 / \mathrm{C} 16$ & $134.94 /{ }^{\mathrm{a}}$ & 133.83 & & \\
\hline $\mathrm{C} 9$ & 59.49 & 55.66 & & \\
\hline \multicolumn{5}{|l|}{ Aromatic $\mathbf{C H}$} \\
\hline C6H6/C3H3 & $124.30 /(123.34)^{\mathrm{b}}$ & \multirow{2}{*}{128.55 and 128.22} & $8.04 /(7.26)^{b}$ & $8.00-7.98(\mathrm{~d})^{\mathrm{c}}$ \\
\hline $\mathrm{C} 14 \mathrm{H} 8 / \mathrm{C} 15 \mathrm{H} 9$ & $124.00 /(126.44)^{\mathrm{b}}$ & & $8.12 /(7.60)^{b}$ & 7.96 \\
\hline $\mathrm{C} 8 \mathrm{H} 7 / \mathrm{C} 1 \mathrm{H} 1$ & $122.24 /(118.22)^{b}$ & 124.23 & $9.99 /(7.78)^{b}$ & 8.04 \\
\hline $\mathrm{C} 5 \mathrm{H} 5 / \mathrm{C} 4 \mathrm{H} 4$ & $116.08 /(116.22)^{b}$ & 120.28 & $8.17 /(8.01)^{\mathrm{b}}$ & $8.12-8.11(\mathrm{~d})$ \\
\hline \multicolumn{5}{|l|}{ Alkylic region } \\
\hline $\mathrm{C} 20 \mathrm{H}_{2} / \mathrm{C} 20{ }^{\prime} \mathrm{H}_{2}$ & $44.85 / 44.64$ & 40.45 & $2.90 / 2.72$ & 2.16 \\
\hline $\mathrm{C} 21 \mathrm{H}_{2} / \mathrm{C} 21^{\prime} \mathrm{H}_{2}$ & $26.68 / 26.49$ & 32.07 & $1.46 / 1.31$ & \multirow{6}{*}{$1.26-1.17$} \\
\hline $\mathrm{C} 22 \mathrm{H}_{2} / \mathrm{C} 22^{\prime} \mathrm{H}_{2}$ & $33.78 / 33.89$ & 30.35 & $1.70 / 1.47$ & \\
\hline $\mathrm{C} 23 \mathrm{H}_{2} / \mathrm{C} 23^{\prime} \mathrm{H}_{2}$ & $33.92 / 33.72$ & 29.52 & $1.39 / 1.32$ & \\
\hline $\mathrm{C} 24 \mathrm{H}_{2} / \mathrm{C} 24^{\prime} \mathrm{H}_{2}$ & $33.98 / 34.04$ & 29.52 & $1.47 / 1.35$ & \\
\hline $\mathrm{C} 25 \mathrm{H}_{2} / \mathrm{C} 25^{\prime} \mathrm{H}_{2}$ & $33.07 / 34.97$ & 24.28 & $1.32 / 1.31$ & \\
\hline $\mathrm{C} 26 \mathrm{H}_{2} / \mathrm{C} 26^{\prime} \mathrm{H}_{2}$ & $26.25 / 26.32$ & 22.85 & $1.16 / 1.10$ & \\
\hline $\mathrm{C} 27 \mathrm{H}_{2} / \mathrm{C} 27^{\prime} \mathrm{H}_{2}$ & $15.95 / 15.95$ & 14.32 & $0.51 / 0.51$ & $0.83-0.80(t)^{c}$ \\
\hline
\end{tabular}

${ }^{a} \mathrm{C} 2$ and $\mathrm{C} 16$ chemical environment in the monomer does not reflect their chemical environment in the polymer. ${ }^{b}$ The chemical environment of these carbon atoms will be strongly affected when going from the monomer to the polymer. " $d$ " stands for doublet and "t" stands for triplet.

due to strong self-absorption, and there is little evidence for $\pi$-stacking. If significant aggregation is occurring in this solvent, this would also be expected to be strongly dependent upon temperature. Spectra were recorded for concentrated and dilute solutions at various temperatures from room temperature to -30 ${ }^{\circ} \mathrm{C}$. However, only slight variations in intensity and band shape and no shifts in emission maxima were observed on cooling. The normalized spectra of the concentrated solution at room temperature and $-30{ }^{\circ} \mathrm{C}$ are compared in Figure 8, and nonnormalized spectra for concentrated and dilute solutions are given as Supporting Information (Figure S1). The lack of spectral shift or quenching of the fluorescence on cooling contrasts with the behavior expected for $\pi$-stacking, such as is seen with poly[2,7-(9,9-bis(2,6-ethylhexyl)fluorene)-alt-1,4-phenylene], where both strong quenching and red-shifts in maxima are seen on going from chloroform solution to thin films. ${ }^{31} \mathrm{We}$ therefore feel that at the concentrations used in the NMR experiments, there is no perturbation of the conjugated polymer backbone due to interchain interactions.

Conformational Effects on NMR Chemical Shifts. The conformation adopted by the backbone of a polymer in solution depends on a variety of factors, including the temperature, the concentration of the polymer, the quality of the solvent, and the nature of both the backbone and any substitution present in the polymer. Polymer backbone conformation influences its physical (crystallinity and molecular packing), electronic, and optical properties, and thus, its use and performance in optoelectronic devices. Several PFs - in particular, poly(9,9-diheptylfluorene-2,7-diyl) (PF7), poly(9,9-dioctylfluorene-2,7-diyl) (PF8), and poly(9,9-dinonylfluorene-2,7-diyl) (PF9)-are known to adopt an almost planar conformation under certain conditions, with torsion angles around $160-165^{\circ}$ (the so-called $\beta$ - phase). ${ }^{13,14,32-39}$ This is important for electronic device applications due to its emission properties. It is, hence, of great interest to obtain tools that easily give us information on backbone conformation and, for example, help in identifying favorable conditions for the formation of the $\beta$-phase. Since NMR chemical shifts report on the behavior on the atomic distance scale and are sensitive even to subtle structural changes, this seems to be an ideal technique for that purpose.

It is expected that the chemical shifts of the aromatic carbons and protons will vary strongly with changes in the interunit torsion angle. In previous studies with fluorene based polymers in solution, $\mathrm{w}^{15}$ have found that the protons of biphenyl, as a model compound, are very sensitive to the torsion angle between the two phenyl units, and another study has analyzed the same effect for ${ }^{13} \mathrm{C}$ NMR shieldings in biphenyl. ${ }^{40}$ Here, we have considered the PF2/6 dimer and the F8BT monomer and have analyzed how selected aromatic ${ }^{1} \mathrm{H}$ and ${ }^{13} \mathrm{C}$ chemical shifts vary with the torsion angle. The alkyl chains at position 9 of the five-membered ring were replaced by methyl groups to reduce computational time. It has been shown that this does not significantly affect the equilibrium geometries ${ }^{41}$ or the molecular orbital distribution. ${ }^{42}$ The results are shown in Figures 9, 10, and 11.

For the PF2/6 dimer, the study shows that the chemical shifts of the carbon atoms C1, C2, and C3 (vide Figure 9) decrease as the structure becomes close to planar (for $0^{\circ}$ and $180^{\circ}$ ) and increase outside these values, reaching a maximum in the neighborhood of $90^{\circ}$ and $270^{\circ}$. The largest variation (ca. 8 ppm) was found for $\mathrm{C} 2$. The ${ }^{1} \mathrm{H}$ shifts ( $\mathrm{Ha}$ and $\mathrm{Hb}$, Figure 9), however, vary in the opposite direction, reaching maximum values at $0^{\circ}$ and $180^{\circ}$ and minimum values close to $90^{\circ}$ and $270^{\circ}$. The reason why ${ }^{1} \mathrm{H}$ and ${ }^{13} \mathrm{C}$ shifts vary in opposite directions with torsion 


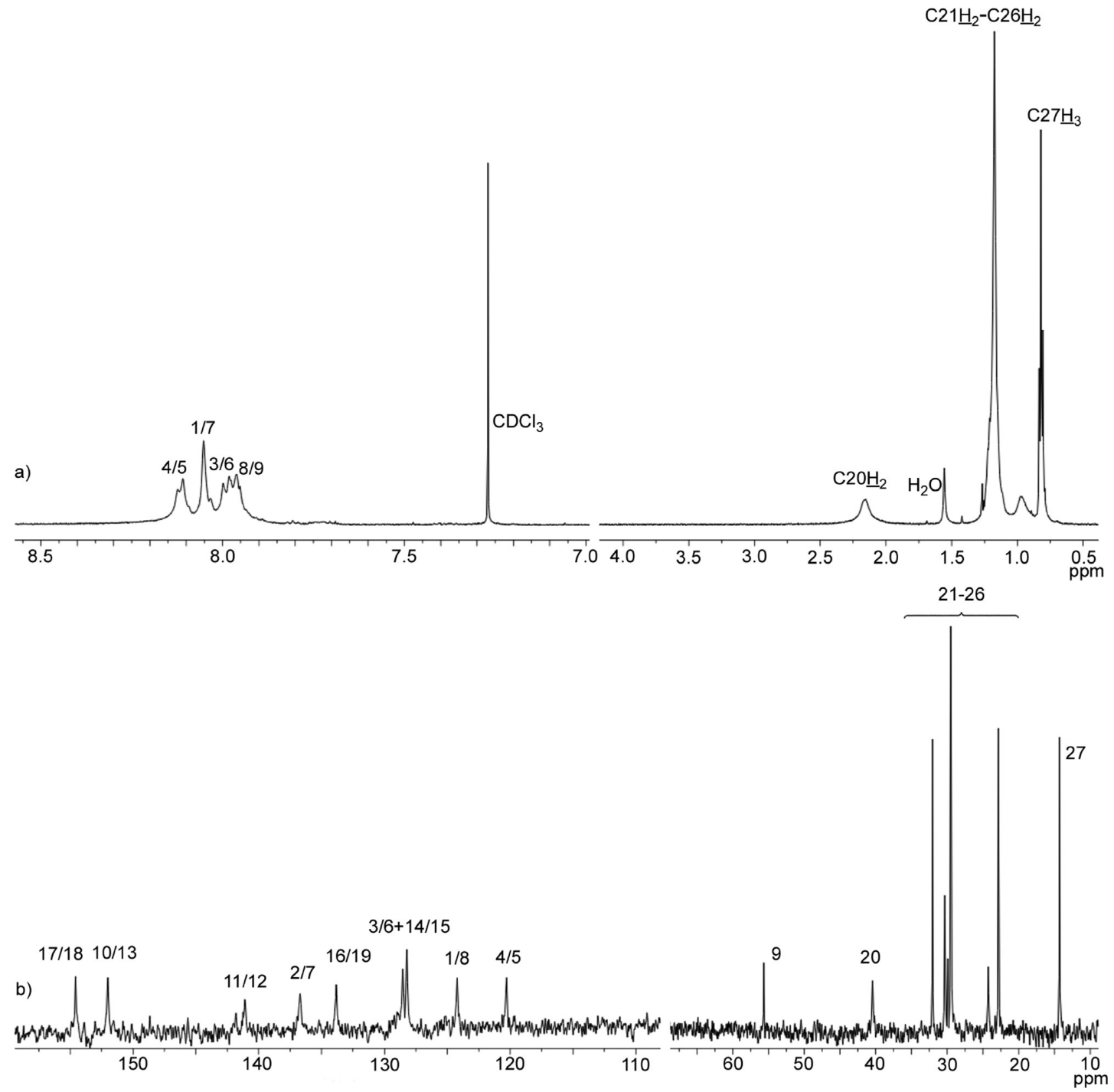

Figure 7. (a) ${ }^{1} \mathrm{H}$ NMR spectrum and (b) ${ }^{13} \mathrm{C}$ NMR spectrum of a F8BT $0.005 \mathrm{M}$ solution (in terms of repeat units) in $\mathrm{CDCl}_{3}$ at $298.15 \mathrm{~K}$ (numbering is as defined in Figure 6).

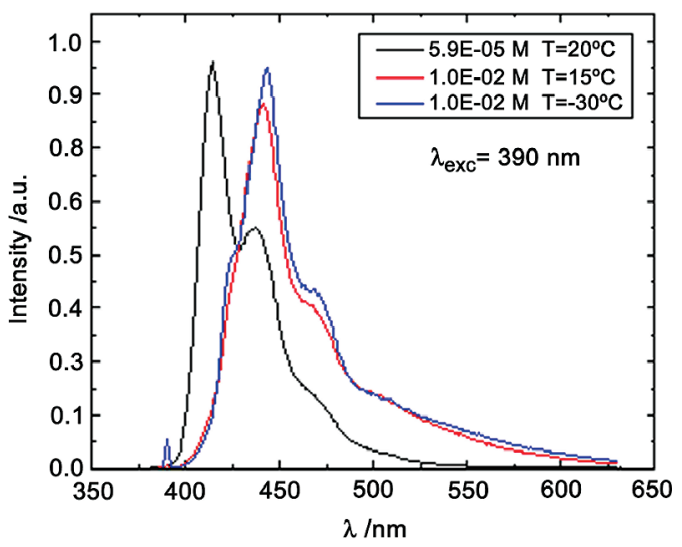

Figure 8. Normalized fluorescence spectra of concentrated solutions of PF2/6 in chloroform $(0.01 \mathrm{M})$ at $15^{\circ}$ and $-30{ }^{\circ} \mathrm{C}$, and comparison with dilute solution $\left(5.9 \times 10^{-5} \mathrm{M}\right)$ at room temperature.

angle is understood in view of the fact that at planar conformations, there is an increase in the electronic conjugation. This increase will lead to the electronic density being more delocalized onto the carbon atoms and further from the hydrogen atoms. We also need to consider that with planar conformations, the calculated distances between $\mathrm{Ha}, \mathrm{Ha}^{\prime}(1.8620 \AA)$ and $\mathrm{Hb}$,
$\mathrm{Hb}^{\prime}(1.8063 \AA)$ are less than the sum of the van der Waals radii ( $2.40 \AA$, using data from ref 43 ) such that the repulsions between electrons will increase, thus affecting their electronic clouds. This depletion of electrons on the ${ }^{1} \mathrm{H}$ atoms will diminish their shielding, and consequently, their chemical shifts increase. The opposite effect occurs with the carbons, with an increased shielding. An alternative explanation, which is possibly equivalent in electronic terms, is in terms of ring currents, in which the opposite effects will be observed with carbon and hydrogen. This is discussed in detail elsewhere. ${ }^{44}$

For the F8BT monomer, we have analyzed the variation of the chemical shift of the $\mathrm{Ha}, \mathrm{Hb}$, and $\mathrm{Hc}$ hydrogen atoms (Figure 10) and of the $\mathrm{C} 1, \mathrm{C} 2, \mathrm{C} 3, \mathrm{C} 4, \mathrm{C} 5$, and C6 carbon atoms (Figure $11)$. For the hydrogen atoms, the pattern of variation is similar to the one obtained for the PF2/6 dimer, with maximum $\delta$ at conformations close to planar and minimum $\delta$ for conformations with torsion angles close to $90^{\circ}$ (and $270^{\circ}$ ).

The chemical shifts of the carbon atoms C2, C4, C5, and C6 reach minimum values at conformations close to planar and increase as the torsion angle approaches $90^{\circ}$ and $270^{\circ}$, similar to what was observed for the PF2/6 dimer. $\mathrm{C} 1$ and $\mathrm{C} 3$, however, have very distinct behaviors as, respectively, they reach maximum and minimum $\delta$ values at $180^{\circ}$ and minimum and 
a)
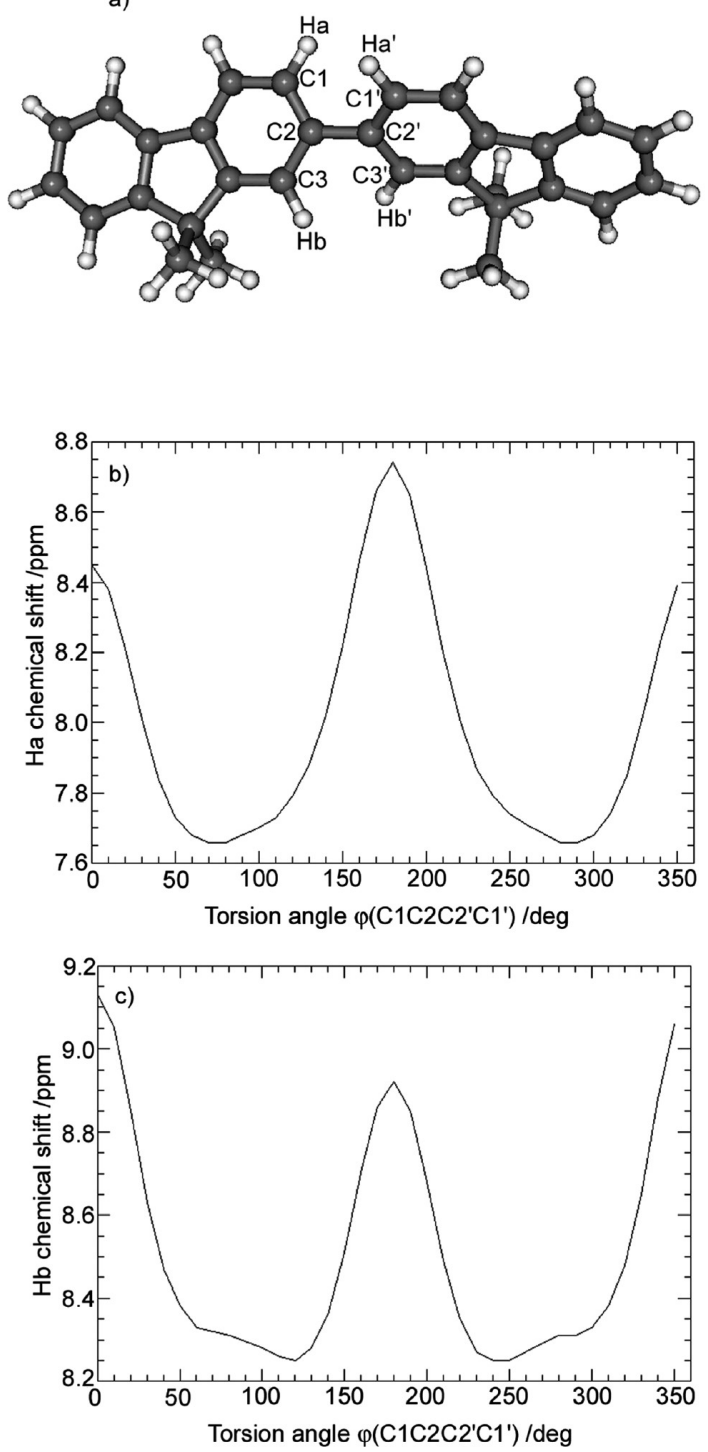
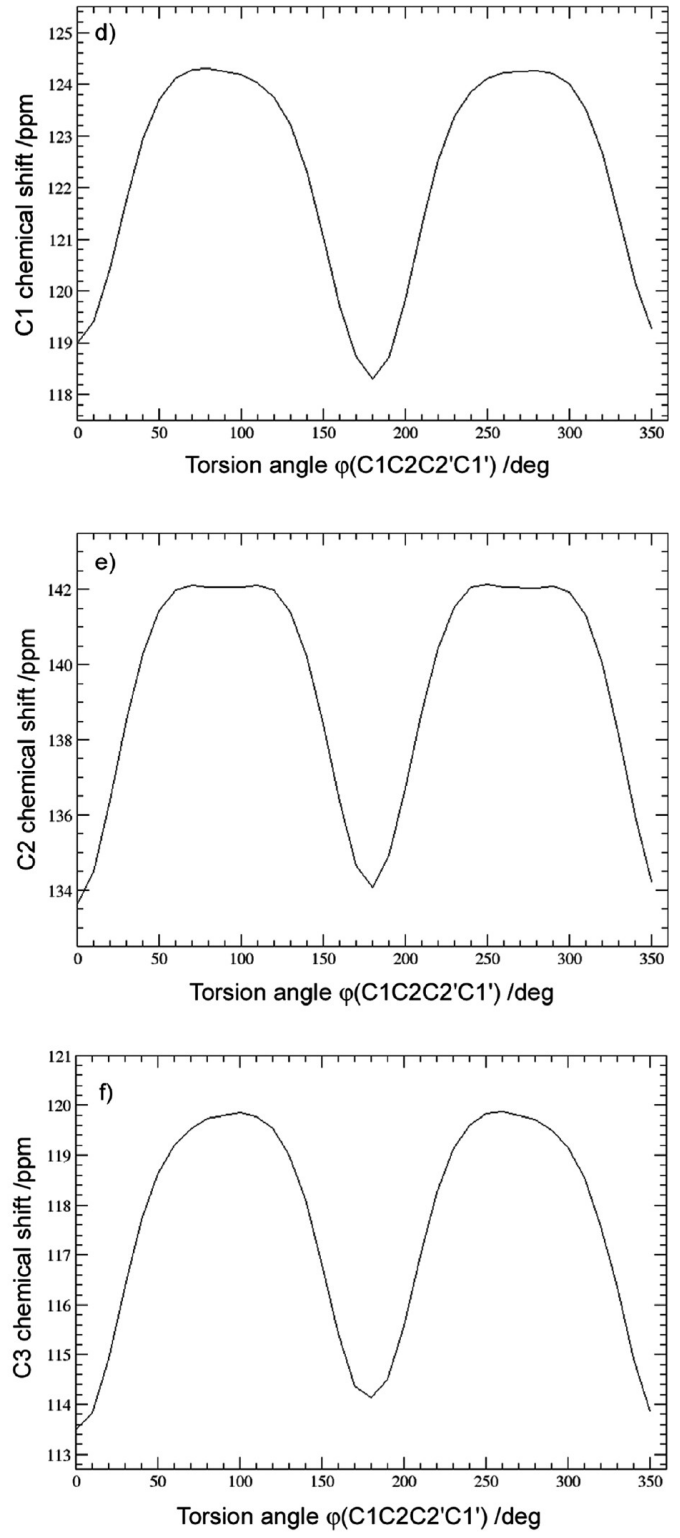

Figure 9. Torsion angle dependence of chemical shifts for the PF2/6 dimer (nonrelaxed): (a) PF2/6 dimer structure at equilibrium; (b) Ha chemical shift dependence; (c) Hb chemical shift dependence; (d) C1 chemical shift dependence; (e) C2 chemical shift dependence; and (f) C3 chemical shift dependence.

maximum $\delta$ values at $0^{\circ}$. This is due to their position relative to the electronegative sulfur and nitrogen atoms of the benzothiadiazole unit. The proximity to the thiadiazole unit has a deshielding effect on these carbon atoms; thus, $\mathrm{C} 1 \delta$ is a maximum at $180^{\circ}$ and $\mathrm{C} 3$ is maximum at $0^{\circ}$.

From the results of Figures 9, 10, and 11, we conclude that the chemical shifts of the carbon and hydrogen atoms in the neighborhood of the interunit bond are sensitive to the torsion angle variation. This means that their experimental (solution or solid state) NMR chemical shifts can be used to probe for backbone conformation. For the PF2/6 dimer, $\mathrm{C} 2$ is the most sensitive carbon, with a $\delta$ variation of $8 \mathrm{ppm}$ for a torsion angle variation from $0^{\circ}$ to $60^{\circ}$. $\mathrm{C} 1$ and $\mathrm{C} 3$ have variations of about 5 and $6 \mathrm{ppm}$. $\mathrm{Ha}$ and $\mathrm{Hb}$ are equally sensitive (about $1 \mathrm{ppm}$ of $\delta$ variation), but $\mathrm{Hb}$ is more sensitive in the region from $0^{\circ}$ to $120^{\circ}$, and $\mathrm{Ha}$ is more sensitive in the region from $70^{\circ}$ to $180^{\circ}$. For the F8BT monomer, $\mathrm{C} 1, \mathrm{C} 2, \mathrm{C} 4$, and $\mathrm{C} 5$ are the most sensitive carbons in the region from $0^{\circ}$ to $90^{\circ}$, with $\delta$ variations from 8 to $5.5 \mathrm{ppm}$. C3, C4, and $\mathrm{C} 5$ are most sensitive in the region from $90^{\circ}$ to $180^{\circ}$, with $\delta$ variations around $7 \mathrm{ppm}$. Ha and $\mathrm{Hb}$ are highly sensitive, with $\delta$ variations about $4 \mathrm{ppm} . \mathrm{Hb}$ is more sensitive from $0^{\circ}$ to $80^{\circ}$ and $\mathrm{Ha}$ from $80^{\circ}$ to $180^{\circ}$.

The results in Figures 9, 10, and 11 do not include the calculated chemical shifts at $90^{\circ}$ and $270^{\circ}$ torsion angles. At these angles, there is a breakdown of the electronic conjugation, and consequently, the ${ }^{13} \mathrm{C}$ and ${ }^{1} \mathrm{H}$ shifts decrease abruptly due to the localization of electron density on the atoms. Because of the breakdown of the electronic conjugation, these conformations are highly unstable.

We will now analyze which conformational changes occur for $\mathrm{PF} 2 / 6$ and $\mathrm{F} 8 \mathrm{BT}$ in $\mathrm{CDCl}_{3}$ solution in the range of temperatures from -50 to $+65{ }^{\circ} \mathrm{C}$ using NMR spectroscopy and using the correlations above to interpret the results. For this, we have obtained the ${ }^{13} \mathrm{C}$ and ${ }^{1} \mathrm{H}$ NMR spectra of the polymers at several temperatures in this range. These are shown in Figures 12, 13, and 14. Figure 12 shows the sequence of the ${ }^{13} \mathrm{C}$ spectra (aromatic region) obtained for F8BT at $-30,25$, and $50{ }^{\circ} \mathrm{C}$. The labeling of the carbon atoms is as defined in Figure 11. There is a clear shift of the resonances of all the aromatic carbon atoms upon the increase of temperature. One 
a)

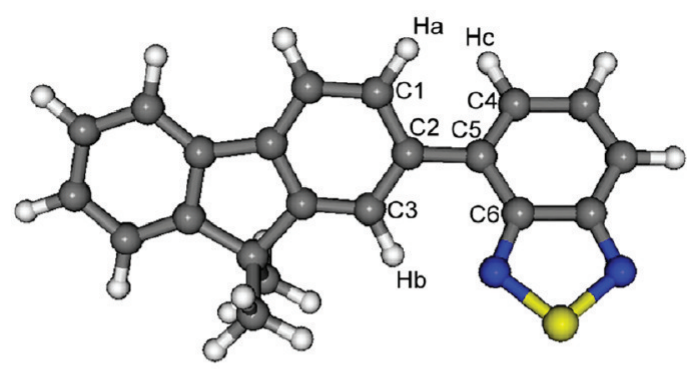

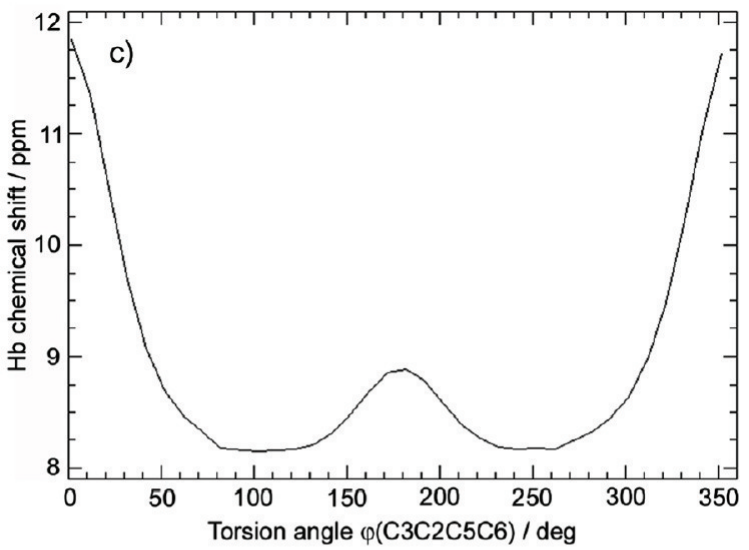

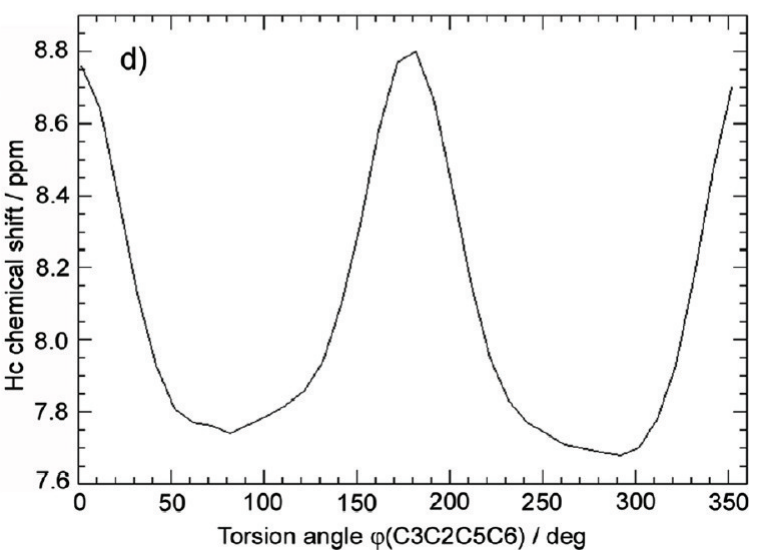

Figure 10. Torsion angle dependence of chemical shifts for the F8FT monomer (nonrelaxed): (a) F8BT monomer structure at equilibrium; (b) Ha chemical shift dependence; (c) Hb chemical shift dependence; and (d) Hc chemical shift dependence.

very important result is that the resonances of $\mathrm{C} 2, \mathrm{C} 3, \mathrm{C} 4, \mathrm{C} 5$, and $\mathrm{C} 6$ all shift to higher frequencies, whereas $\mathrm{C} 1$ has the opposite behavior, going to a lower frequency. This exact behavior, with an increase in $\mathrm{C} 2, \mathrm{C} 3, \mathrm{C} 4, \mathrm{C} 5$, and $\mathrm{C} 6$ chemical shifts and a decrease in the $\mathrm{C} 1$ chemical shift is described by the curves in Figure 11 for a change in torsion angle from $180^{\circ}$ to $90^{\circ}$. This means that this result alone allows us to conclude that with a change in temperature from -30 to $+50{ }^{\circ} \mathrm{C}$, the torsion angle of F8BT backbone decreases within the range of $180-90^{\circ}$; that is, F8BT starts with a more planar conformation at $-30{ }^{\circ} \mathrm{C}$, with a torsion somewhere between $180^{\circ}$ and $90^{\circ}$, and as the temperature rises, the torsion angle decreases still farther from planarity.

The ${ }^{1} \mathrm{H}$ NMR results are more difficult to analyze because several factors seem to be causing the shift of the resonances as the temperature increases. In Figures 13 and 14, we show a series of ${ }^{1} \mathrm{H}$ spectra of the $\mathrm{F} 8 \mathrm{BT}$ and $\mathrm{PF} 2 / 6$ polymers, respectively, at temperatures between -50 and $+65{ }^{\circ} \mathrm{C}$. From the conclusions obtained from the ${ }^{13} \mathrm{C}$ results of F8BT and noting that the curves in Figures 10 and 11 indicate that ${ }^{1} \mathrm{H}$ and ${ }^{13} \mathrm{C}$ chemical shifts show the opposite behavior upon torsion angle variation, we expect $\mathrm{Ha}, \mathrm{Hb}$, and $\mathrm{Hc}$ resonances to shift to lower frequency as the temperature is raised (cf. curves of Figures 10 and 11). This is, in fact, what happens for Ha and Hc. These signals shift to lower frequencies, in agreement with the ${ }^{13} \mathrm{C}$ results. The same is observed for Ha of PF2/6 (Figure 14). Additionally, the farthest downfield ${ }^{1} \mathrm{H}$ signal of each polymer (H4/H5, Figures 2 and 6) also shifts to lower frequency upon increasing temperature. If aggregation was occurring, this would happen with the decrease in the temperature. When going to lower temperatures, the $\mathrm{Ha}$ and $\mathrm{Hc}$ aromatic proton resonances and the farthest downfield ${ }^{1} \mathrm{H}$ resonance of each polymer all shift to higher frequencies. This contrasts with the behavior of model systems of stacking interactions in polyfluorenes, where experimental ${ }^{45}$ and theoretical ${ }^{46}$ studies indicate there is a shift to lower frequency of the aromatic ${ }^{1} \mathrm{H}$ resonances of at least $0.5-0.7 \mathrm{ppm}$ on $\pi$-stacking. Similarly, in the study of Rahman et al. on the changes in NMR upon aggregation of PF2/6 in toluene, ${ }^{17}$ a shift to lower frequency was observed with all the aromatic protons of the polymer, whereas the solvent protons were split. As noted above, the shift in the $\mathrm{Ha}$ and $\mathrm{Hc}$ aromatic protons and the farthest downfield ${ }^{1} \mathrm{H}$ signal of each polymer is in the opposite direction, and there is no splitting of the solvent signal. We thus feel, in agreement with the fluorescence studies and with previous reports of chloroform being a good solvent for fluorene-based polymers, ${ }^{8,36}$ that there are no significant interchain interactions resulting from aggregation that affect the backbones of these conjugated polymers. However, in addition to the conformational effect on the backbone, there are other factors that appear to be acting when the temperature is decreased, and their effects are visible mainly for the alkylic resonances and for the $\mathrm{Hb}$ aromatic protons of both F8BT and PF2/6, which do shift to lower frequency. With the observed temperature dependence, one factor that can contribute to the behavior is polymer-solvent interaction, since for this kind of polymers, in a good organic solvent such as chloroform, these may be stronger at higher temperature. In addition, solvation will affect different parts of the molecule in different ways, depending on electronic dipoles and polarizability. The increase in intensity of the polymer-solvent interactions at higher temperatures leads to a deshielding of the ${ }^{1} \mathrm{H}$ shifts, causing the shift to higher frequencies observed for the alkylic and the $\mathrm{Hb}$ protons. In fact, these downfield ${ }^{1} \mathrm{H}$ shifts at higher temperatures reflect the good solubility of these polymers in 

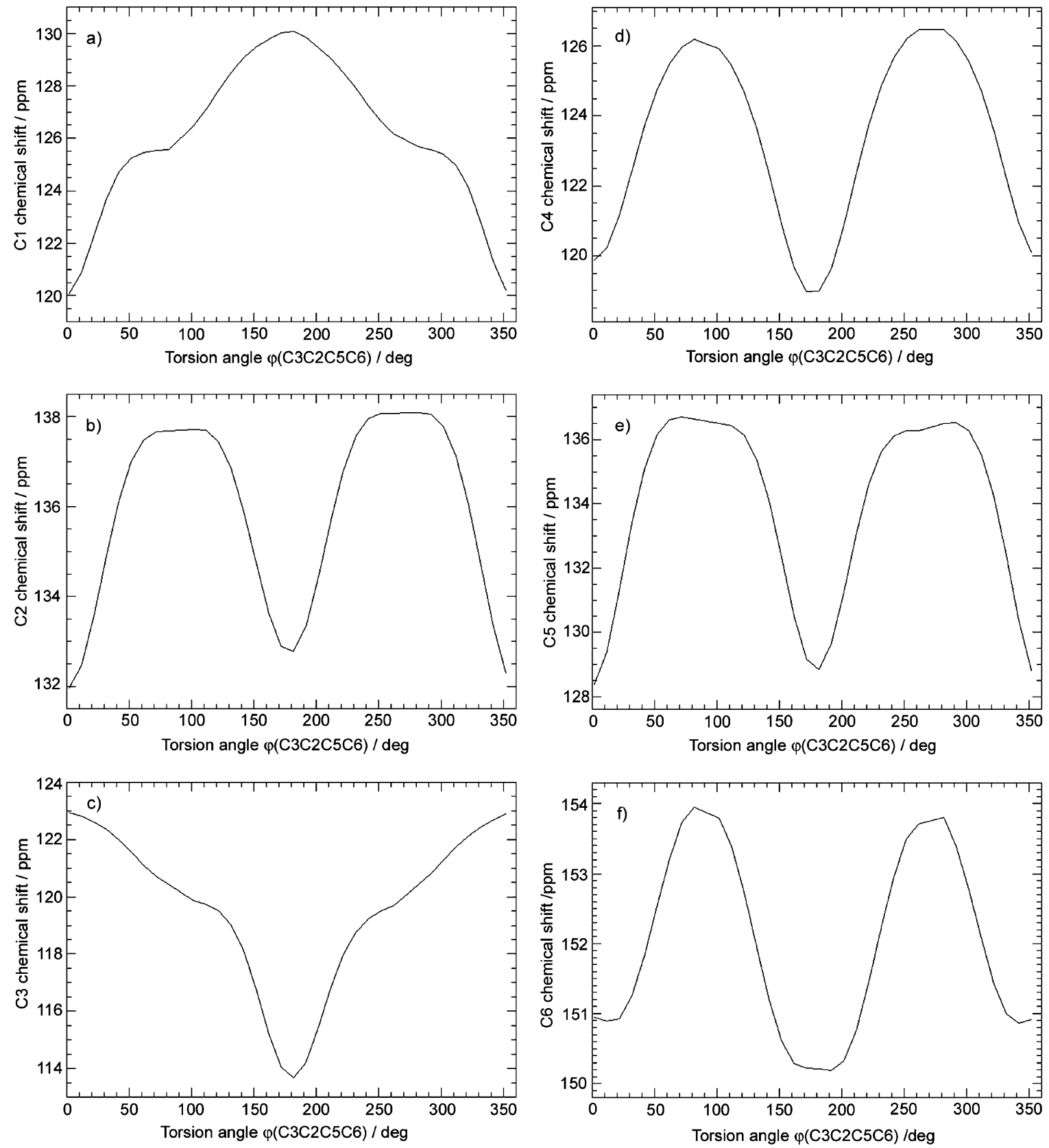

Figure 11. Torsion angle dependence of the chemical shifts of (a) $\mathrm{C} 1$, (b) C2, (c) C3, (d) C4, (e) C5, and (f) C6 carbon atoms of the F8FT monomer (computed at the B3LYP/6-31G(d,p)//B3LYP/6-31G(d,p) level).

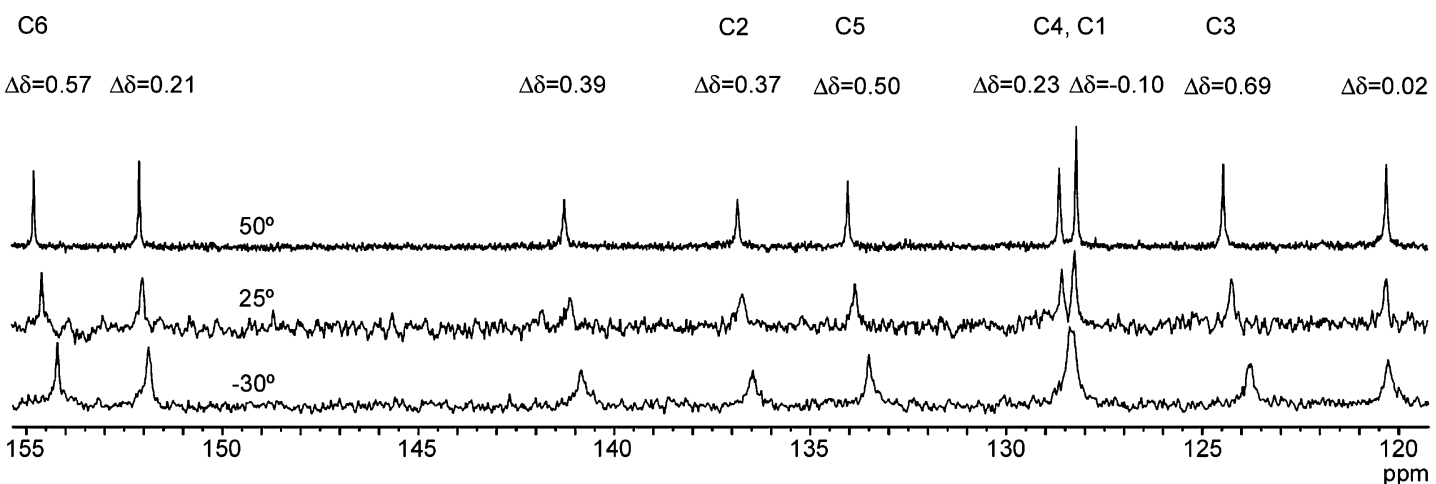

Figure 12. Expanded view of the aromatic region of the ${ }^{13} \mathrm{C}$ NMR spectra of a $0.022 \mathrm{M}$ F8BT solution (in terms of repeat units) in $\mathrm{CDCl}_{3}$ at indicated temperatures.

chloroform. Supporting the role of solvation for PF2/6 is the fact that the signals most affected by this downfield effect are the alkylic $\mathrm{CH}_{2}$ proton signals $(\Delta \delta=+0.13)$, and these hydrogen atoms are located in the region of higher polarizability 


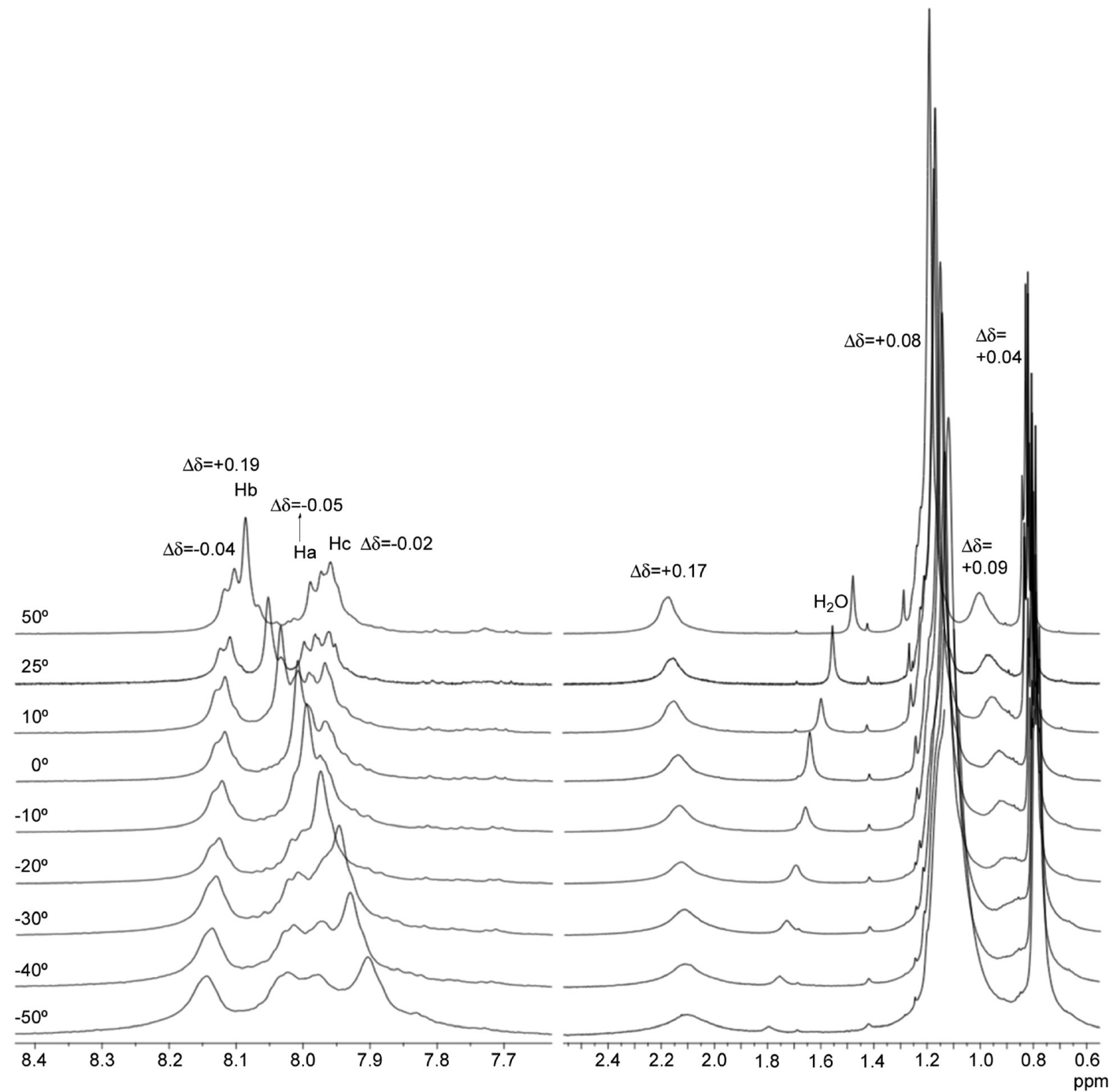

Figure 13. ${ }^{1} \mathrm{H}$ NMR spectra $(500 \mathrm{MHz})$ of a $0.022 \mathrm{M}$ F8BT solution (in terms of repeat units) in $\mathrm{CDCl}_{3}$ at indicated temperatures. The water signal shift to lower frequency upon the increase in temperature is due to variation of the intensity of the intermolecular forces. With the increase in temperature, the hydrogen bonds become weaker, and this translates into a shielding of the ${ }^{1} \mathrm{H}$ resonance of the water molecules.

of the molecule. In contrast, for F8BT, the most affected hydrogen atoms are $\mathrm{Hb}(\Delta \delta=+0.19)$ and the first $\mathrm{CH}_{2}$ hydrogen atoms of the alkylic chain (closer to the fluorene moiety) $(\Delta \delta=+0.17)$. In F8BT, these hydrogen atoms are very close to the positive side of the benzothiadiazole dipole (since the torsion angle is some value between $180^{\circ}$ and $90^{\circ}$ ). This means that the electronegative chlorine atoms of the solvent (chloroform) will be attracted to this region and the interactions with the solvent will be stronger in this region compared with the rest of the polymer. However, the behavior of $\mathrm{Hb}$ in F8BT appears to parallel in part that of the methylene group attached to the 9-position of the aromatic ring, suggesting the possibility that interactions of $\mathrm{Hb}$ with the alkylic chain may also be important. With PF2/6, this interaction is unfavorable, and in contrast to the behavior with F8BT, the Hb proton of PF2/6 shows only a small shift on changing temperature.

For PF2/6, temperature-induced conformational rearrangement of the alkyl chains can also contribute to the shift of the resonance of the $\mathrm{CH}_{2}$ protons $(\Delta \delta=+0.13)$. Figure 15 shows an expanded view of some of the PF2/6 spectra of Figure 14. In the sequence of spectra, in addition to the shift of the $\mathrm{CH}_{2}$ and $\mathrm{CH}_{3}$ resonances to higher frequency, we observe the growth of the shoulder at $\delta \sim 0.88 \mathrm{ppm}$ upon increasing temperature. The growth of this shoulder probably corresponds to an increase in gauche conformations in the alkylic chains as the thermal energy approaches the energetic barrier for the trans-to-gauche transformation.

It is also interesting to note that the curves of ${ }^{1} \mathrm{H}$ chemical shift as a function of torsion angle (Figures 9 and 10) predict, as found experimentally, that Ha is substantially more sensitive than $\mathrm{Hb}$ or $\mathrm{Hc}$ to torsional changes in the range $180^{\circ}$ to $90^{\circ}$. Furthermore, those curves predict the larger sensitivity of $\mathrm{Ha}$ of F8BT, as compared to Ha of PF2/6.

Summarizing, we can conclude that the correlations between torsion angle and ${ }^{1} \mathrm{H}$ and ${ }^{13} \mathrm{C}$ chemical shifts presented in Figures 9, 10, and 11 can be used to interpret NMR spectral changes with external factors, such as temperature, and obtain information on backbone conformational changes. The conclusions and correlations obtained for PF2/6 are similar to those obtained for F8BT. We feel, therefore, that it is reasonable to extend these correlations in a qualitative way to all PFs.

The conclusions obtained from our NMR study of PF2/6 and F8BT concerning conformational changes with temperature are also in agreement with other recent results. Our results indicate that upon a decrease in temperature, F8BT and PF2/6 adopt conformations that are closer to planarity. This agrees with the results obtained by Bright et al., ${ }^{39}$ who found that $\beta$-phase 


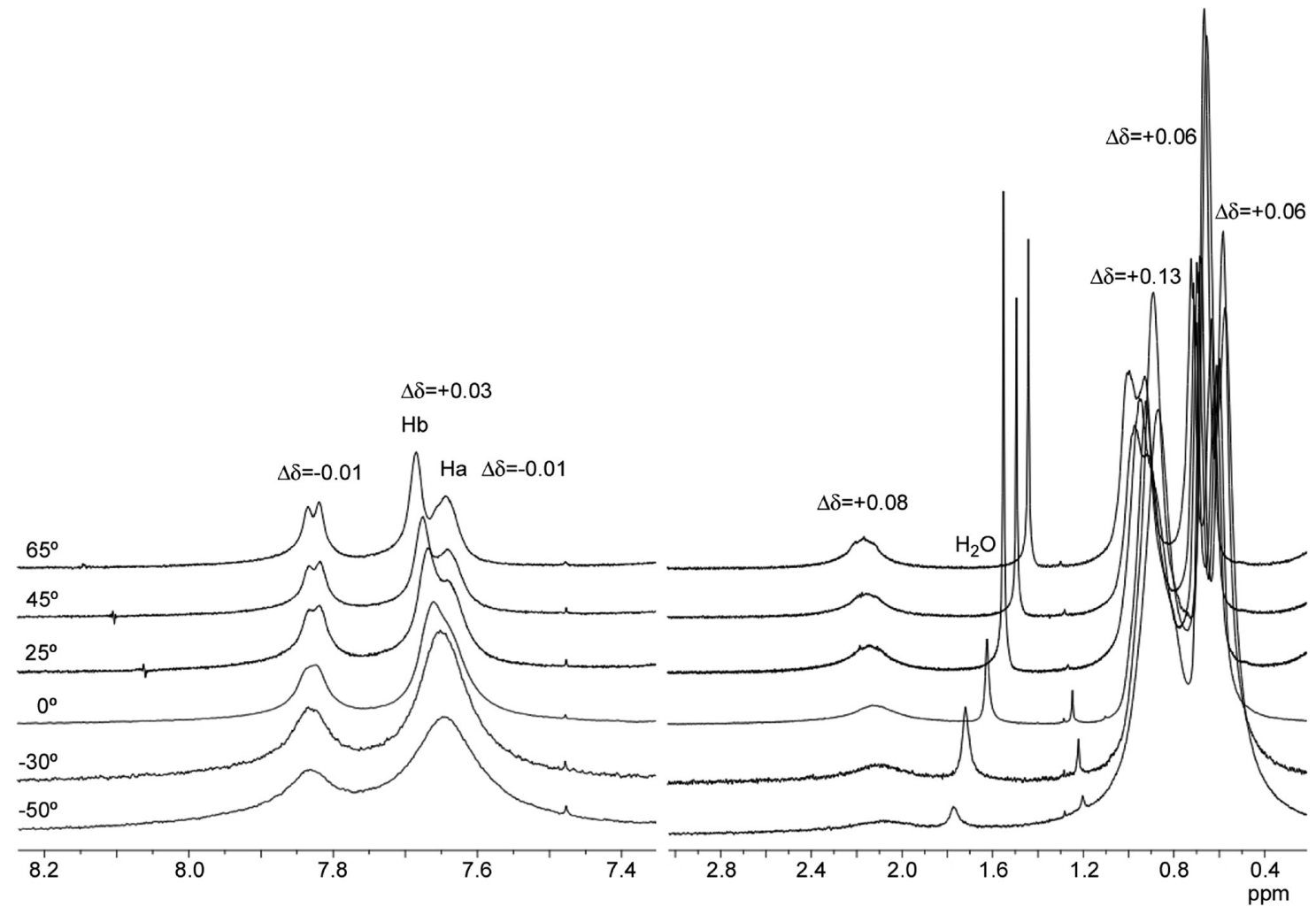

Figure 14. ${ }^{1} \mathrm{H}$ NMR spectra $(500 \mathrm{MHz})$ of a $0.01 \mathrm{M} \mathrm{PF} 2 / 6$ solution (in terms of repeat units) in $\mathrm{CDCl}_{3}$ at indicated temperatures. For water signal resonance shift, see explanation in caption of Figure 13.

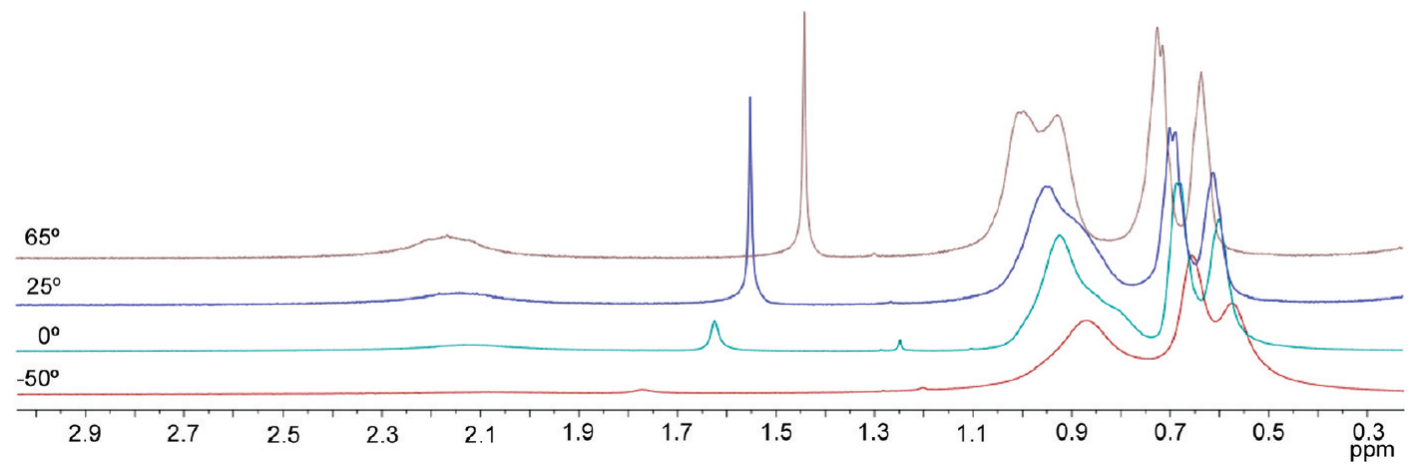

Figure 15. Expanded view of the alkylic region of the ${ }^{1} \mathrm{H}$ NMR spectra of a $0.01 \mathrm{M} \mathrm{PF} 2 / 6$ solution (in terms of repeat units) in $\mathrm{CDCl}_{3}$ at indicated temperatures.

(suggested to consist of an almost planar conformation) is favored by cooling solutions of PF7, PF8, and PF9.

\section{Conclusions}

Density functional theory methods were used to calculate the aromatic ${ }^{1} \mathrm{H}$ and ${ }^{13} \mathrm{C}$ NMR chemical shifts as a function of the interunit torsion angle for the PF2/6 dimer and for the F8BT monomer. This approach allowed us to obtain a series of property-structure (NMR chemical shift-backbone torsion) relationships that can be used to analyze NMR spectral data of poly(9,9-dialkylfluorenes) and obtain information on backbone conformation changes upon some external factor, such as temperature, polymer concentration, or solvent. Both the aromatic ${ }^{1} \mathrm{H}$ and ${ }^{13} \mathrm{C}$ resonances were found to be sensitive to interunit torsion angle variation. Except for the $\mathrm{C} 1$ and $\mathrm{C} 3$ carbon atoms of F8BT, which have particular behaviors due to their proximity to the thiadiazole unit, all the other aromatic carbon atoms of PF2/6 and F8BT that were considered in the study reach maximum chemical shift values at $90^{\circ}$ torsion and minimum values at planar conformations $\left(0^{\circ}\right.$ and $\left.180^{\circ}\right)$. In contrast, the ${ }^{1} \mathrm{H}$ chemical shifts have maximum values for planar conformations and minimum values for $90^{\circ}$ conformations. A series of ${ }^{1} \mathrm{H}$ and ${ }^{13} \mathrm{C}$ NMR spectra were obtained for the polymers $\mathrm{PF} 2 / 6$ and $\mathrm{F} 8 \mathrm{BT}$ in chloroform at temperatures between -50 and $+65{ }^{\circ} \mathrm{C}$. The changes observed in the ${ }^{1} \mathrm{H}$ and ${ }^{13} \mathrm{C}$ spectra indicate that with an increase in temperature, the backbone torsion of both polymers varies in the range from $180^{\circ}$ to $90^{\circ}$, getting farther from planarity. The ${ }^{13} \mathrm{C}$ chemical shifts were found to be more readily interpreted, since some of the ${ }^{1} \mathrm{H}$ resonances are susceptible to opposing effects (including increasing solvation of the side groups). The resonances in the ${ }^{1} \mathrm{H}$ and ${ }^{13} \mathrm{C}$ NMR spectra of the two polymers were attributed prior to the calculation of the relationships between torsion angle and NMR chemical shifts. For that, we have obtained the DEPT and HETCOR spectra of one of the polymers, and we have calculated the ${ }^{1} \mathrm{H}$ and ${ }^{13} \mathrm{C}$ shielding constants for the PF2/6 and F8BT monomers using DFT/GIAO methods. We have tested several DFT levels of calculation for optimizing the structures 
and for calculating the shielding constants, and the method B3LYP/6-31G(d,p) was found to give the best results in both cases.

Acknowledgment. Professor Jorge Morgado of the Instituto Superior Técnico, Lisbon, Portugal, is acknowledged for providing the F8BT polymer. L.L.G.J. thanks Fundação para a Ciência e a Tecnologia (FCT), of the Portuguese Ministry for Science, Technology and Higher Education, for the postdoctoral grant SFRH/BPD/26415/2006 and the Laboratório de Computação Avançada, of the Department of Physics of the University of Coimbra, for the computing facilities (Milipeia Cluster). We are indebted to R. Rondão and Professor J. Seixas de Melo for their generous assistance with the fluorescence measurements. H.D.B. thanks the FCT for a Sabbatical Leave Grant (SFRH/ BSAB/886/2009) and the Center for Photochemical Sciences, Bowling Green State University, Bowling Green, Ohio, for their hospitality.

Supporting Information Available: Variable temperature fluorescence spectra of PF2/6 in chloroform solution. This material is available free of charge via the Internet at http:// pubs.acs.org.

\section{References and Notes}

(1) Friend, R. H.; Gymer, R. W.; Holmes, A. B.; Burroughes, J. H.; Taliani, C.; Bradley, D. D. C.; Dos Santos, D. A.; Bredas, J. L.; Logdlund, M.; Salaneck, W. R. Nature 1999, 397, 121.

(2) Pivrikas, A.; Sariciftci, N. S.; Juska, G.; Osterbacka, R. Prog. Photovoltaics 2007, 15, 677.

(3) Knaapila, M.; Winokur, M. J. Adv. Polym. Sci. 2008, 212, 227.

(4) Psaltis, D.; Mok, F. Sci. Am. 1995, 273, 52.

(5) Möller, S.; Perlov, C.; Jackson, W.; Taussig, C.; Forrest, S. R. Nature 2003, 426, 166.

(6) Bernius, M. T.; Inbasekaran, M.; Woo, E.; Wu, W.; Wujkowski, L. J. Mater. Sci.-Mater. Electron. 2000, 11, 111.

(7) Leclerc, M. J. Polym. Sci., Part A: Polym. Chem. 2001, 39, 2867.

(8) Scherf, U.; List, E. J. W. Adv. Mater. 2002, 14, 477.

(9) Polyfluorenes; Scherf, U., Neher, D., Eds.; Springer-Verlag; Berlin, Heidelberg, 2008.

(10) Fytas, G.; Nothofer, H. G.; Scherf, U.; Vlassopoulos, D.; Meier, G. Macromolecules 2002, 35, 481.

(11) Lieser, G.; Oda, M.; Miteva, T.; Meisel, A.; Nothofer, H.-G.; Scherf, U. Macromolecules 2000, 33, 4490 .

(12) Knaapila, M.; Lyons, B. P.; Kisko, K.; Foreman, J. P.; Vainio, U.; Mihaylova, M.; Seeck, O.; Pälsson, L.-O.; Serimaa, R.; Torkkeli, M.; Monkman, A. P. J. Phys. Chem. B 2003, 107, 12425.

(13) Chunwaschirasiri, W.; Tanto, B.; Huber, D. L.; Winokur, M. J. Phys. Rev. Lett. 2005, 94, 107402.

(14) Knaapila, M.; Garamus, V. M.; Dias, F. B.; Almásy, L.; Galbrecht, F.; Charas, A.; Morgado, J.; Burrows, H. D.; Scherf, U.; Monkman, A. P. Macromolecules 2006, 39, 6505.

(15) Knaapila, M.; Almásy, L.; Garamus, V. M.; Ramos, M. L.; Justino, L. L. G.; Galbrecht, F.; Preis, E.; Scherf, U.; Burrows, H. D.; Monkman, A. P. Polymer 2008, 49, 2033.

(16) Knaapila, M.; Stepanyan, R.; Torkeli, M.; Garamus, V. M.; Galbrecht, G.; Nehls, B. S.; Preis, E.; Scherf, U.; Monkman, A. P. Phys. Rev. E 2008, 77, 051803.

(17) Rahman, M. H.; Liao, S. C.; Chen, H.-L.; Chen, J. H.; Ivanov, V. A.; Chu, P. P. J.; Chen, S. A. Langmuir 2009, 25, 1667.

(18) Rahman, M. H.; Chen, C.-Y.; Chen, S.-C.; Chen, H.-L.; Tsao, C.S.; Chen, J.-H-; Ivanov, V. A.; Chen, S. A. Macromolecules 2007, 40, 6572

(19) Ranger, M.; Rondeau, D.; Leclerc, M. Macromolecules 1997, 30 , 7686.

(20) Bernius, M. T.; Inbasekaran, M.; O’Brien, J.; Wu, W. Adv. Mater. 2000, $12,1737$.
(21) Grozema, F. C.; Candeias, L. P.; Swart, M.; Van Duijnen, P. Th.; Wildemen, J.; Hadziioanou, G.; Siebbeles, L. D. A.; Warman, J. M. J. Chem. Phys. 2002, 117, 11366.

(22) Ling, J.; Fomina, N.; Rasul, G.; Hogen-Esch, T. E. J. Phys. Chem. $B$ 2008, 112, 10116

(23) Schmidt, M. W.; Baldridge, K. K.; Boatz, J. A.; Elbert, S. T.; Gordon, M. S.; Jensen, J. H.; Koseki, S.; Matsunaga, N.; Nguyen, K. A.; Su, S. J.; Windus, T. L.; Dupuis, M.; Montgomery, J. A. J. Comput. Chem. $1993,14,1347$.

(24) Becke, A. D. J. Chem. Phys. 1993, 98, 5648

(25) Lee, C.; Yang, W.; Parr, R. G. Phys. Rev. B 1988, 37, 785.

(26) Bylaska, E. J.; de Jong, W. A.; Govind, N.; Kowalski, K.; Straatsma, T. P.; Valiev, M.; Wang, D.; Apra, E.; Windus, T. L.; Hammond, J.; Nichols, P.; Hirata, S.; Hackler, M. T.; Zhao, Y.; Fan, P.-D.; Harrison, R. J.; Dupuis, M.; Smith, D. M. A.; Nieplocha, J.; Tipparaju, V.; Krishnan, M.; Wu, Q.; Van Voorhis, T.; Auer, A. A.; Nooijen, M.; Brown, E.; Cisneros, G.; Fann, G. I.; Fruchtl, H.; Garza, J.; Hirao, K.; Kendall, R.; Nichols, J. A.; Tsemekhman, K.; Wolinski, K.; Anchell, J.; Bernholdt, D.; Borowski, P.; Clark, T.; Clerc, D.; Dachsel, H.; Deegan, M.; Dyall, K.; Elwood, D.; Glendening, E.; Gutowski, M.; Hess, A.; Jaffe, J.; Johnson, B.; Ju, J.; Kobayashi, R.; Kutteh, R.; Lin, Z.; Littlefield, R.; Long, X.; Meng, B.; Nakajima, T.; Niu, S.; Pollack, L.; Rosing, M.; Sandrone, G.; Stave, M.; Taylor, H.; Thomas, G.; van Lenthe, J.; Wong, A. Zhang, Z. NWChem, A Computational Chemistry Package for Parallel Computers, Version 5.1; Pacific Northwest National Laboratory: Richland, Washington 99352-0999, 2007. Kendall, R. A.; Apra, E.; Bernholdt, D. E.; Bylaska, E. J.; Dupuis, M.; Fann, G. I.; Harrison, R. J.; Ju, J.; Nichols, J. A.; Nieplocha, J.; Straatsma, T. P.; Windus, T. L.; Wong, A. T. High Performance Computational Chemistry: An Overview of NWChem a Distributed Parallel Application. Comput. Phys. Commun. 2000, 128, 260.

(27) Grell, M.; Knoll, W.; Lupo, D.; Meisel, A.; Miteva, T.; Neher, D.; Nothofer, H.-G.; Scherf, U.; Yasuda, A. Adv. Mater. 1999, 11, 671.

(28) Fonseca, S. M.; Pina, J.; Arnaut, L. G.; Seixas de Melo, J.; Burrows, H. D.; Chattophadhyay, N.; Alcácer, L.; Charas, A.; Morgado, J.; Monkman, A. P.; Asawapirom, U.; Scherf, U.; Edge, R.; Navaratnam, S. J. Phys. Chem. $B$ 2006, 110,8278 .

(29) Miller, J. N., Ed.; Standards in Fluorescence Spectrometry; Chapman and Hall: London, 1981.

(30) Yamamoto, O.; Someno, K.; Wasasa, N.; Hiraishi, J.; Hayamizu, K.; Tanabe, K.; Tamura, T.; Yanagisawa, M. Anal. Sci. 1988, 4, 233. http:// www:aist.go.jp/RIODB/SDBS.

(31) Charas, A.; Morgado, J.; Martinho, J. M. G.; Alcácer, L.; Lim, S. F.; Friend, R. H.; Cacialli, F. Polymer 2003, 44, 1843.

(32) Bradley, D. D. C.; Grell, M.; Long, X.; Mello, H.; Grice, A.; Inbasekaran, M.; Woo, E. P. Proc. SPIE 1997, 3145, 254.

(33) Grell, M.; Bradley, D. D. C.; Long, X.; Chamberlain, T.; Inbasekaran, M.; Woo, E. P.; Soliman, M. Acta Polym. 1998, 49, 439.

(34) Grell, M.; Bradley, D. D. C.; Ungar, G.; Hill, J.; Whitehead, K. S. Macromolecules 1999, 32, 5810.

(35) Cadby, A. J.; Lane, P. A.; Wohlgenannt, M.; An, C.; Vardeny, Z. V.; Bradley, D. D. C. Synth. Met. 2000, 111-112, 515.

(36) Blondin, P.; Bouchard, J.; Beaupré, S.; Belletête, M.; Durocher, G.; Leclerc, M. Macromolecules 2000, 33, 5874.

(37) Teetsov, J.; Fox, M. A. J. Mater. Chem. 1999, 9, 2117.

(38) Dias, F. B.; Morgado, J.; Maçanita, A. L.; da Costa, F. P.; Burrows, H. D.; Monkman, A. P. Macromolecules 2006, 39, 5854.

(39) Bright, D. W.; Dias, F. B.; Galbrecht, F.; Scherf, U.; Monkman, A. P. Adv. Funct. Mater. 2009, 19, 67.

(40) Ando, S.; Hironaka, T.; Kurosu, H.; Ando, I. Magn. Reson. Chem. 2000, 38, 241.

(41) Belletête, M.; Beaypré, S.; Bouchard, J.; Blondin, P.; Leclerc, M.; Durocher, G. J. Phys. Chem. B 2000, 104, 9118.

(42) Pal, B.; Yen, W.-C.; Yang, J.-S.; Chao, C.-Y.; Hung, Y.-C.; Lin, S.-T.; Chuang, C.-H.; Chen, C.-W.; Su, W.-F. Macromolecules 2008, 41, 6664

(43) Bondi, A. J. Phys. Chem. 1964, 68, 441.

(44) Gunther, H. NMR Spectroscopy, An Introduction; translated by Gleason, R. W.; John Wiley, Chichester, 1980.

(45) Rathore, R.; Abdelwahed, S. H.; Guzei, I. A. J. Am. Chem. Soc. 2003, 125,8712

(46) Kim, W. S.; Kim, J.; Park, J. K.; Mukamel, S.; Rhee, S. K.; Choi, Y. K.; Lee, J. Y. J. Phys. Chem. B 2005, 109, 2686.

JP902666E 